\title{
Development of Standardized Cooking Fires for Evaluation of Prevention Technologies: Phase One Data Analysis
}

\author{
Joshua B. Dinaburg \\ Daniel T. Gottuk \\ Hughes Associates \\ Baltimore, MD 21227
}

This publication is available free of charge from:

http://dx.doi.org/10.6028/NIST.GCR.15-917-35

and www.nfpa.org/foundation

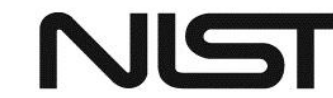

National Institute of Standards and Technology U.S. Department of Commerce 


\title{
Development of Standardized Cooking Fires for Evaluation of Prevention Technologies: Phase One Data Analysis
}

\author{
Prepared for \\ U.S. Department of Commerce \\ Engineering Laboratory
}

National Institute of Standards and Technology

Gaithersburg, MD 20899-6880

Joshua B. Dinaburg

Daniel T. Gottuk

In collaboration with the Fire Protection Research Foundation

This publication is available free of charge from: http://dx.doi.org/10.6028/NIST.GCR.15-917-35 and www.nfpa.org/foundation

October 2013

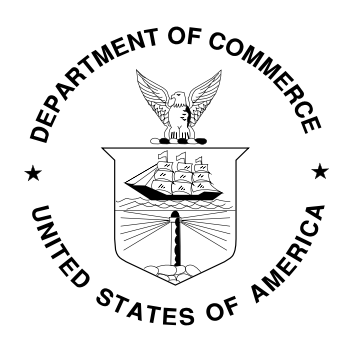

U.S. Department of Commerce

Penny Pritzker, Secretary

National Institute of Standards and Technology Willie May, Under Secretary of Commerce for Standards and Technology and Director 


\title{
Development of Standardized Cooking Fires for Evaluation of Prevention Technologies: Phase One Data Analysis
}

\author{
Final Report
}

Prepared by:

Joshua B. Dinaburg

Dr. Daniel T. Gottuk

Hughes Associates, Inc.

Baltimore, Maryland
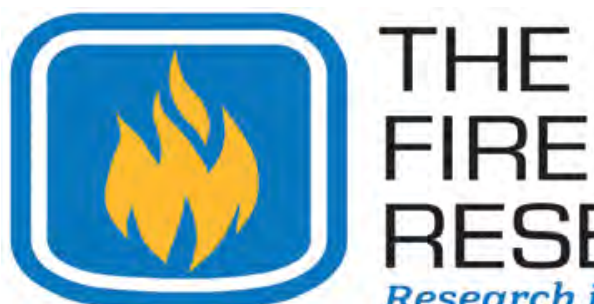

FIRE PROTECTION

RESEARCH FOUNDATION

Research in support of the NFPA mission

The Fire Protection Research Foundation

One Batterymarch Park

Quincy, MA, USA 02169-7471

Email: foundation@nfpa.org

http://www.nfpa.org/foundation 


\section{FOREWORD}

Cooking-equipment related fires are a leading cause of U.S. fire loss. Beginning in the mid 1980's, the National Institute of Standards and Technology, Consumer Product Safety Commission, and home appliance industry undertook a comprehensive review of strategies to mitigate death, injury and property loss from cooking fires. All strategies were engineering strategies defined by a condition to be detected (e.g., overheat of pan or food in pan, absence of person actively engaged in cooking process, early-stage fire on stovetop) and an action to be taken (e.g., shut off cooking heat, sound alarm, suppress fire). As part of this study, a comprehensive review of existing technologies was done.

In 2010, the Foundation conducted a study supported by NIST to develop this action plan. The study focused particularly on prevention technologies suitable for use on or with home cooking appliances. and consisted of a literature and technology review; the development of an enhanced technology evaluation methodology based on an in-depth review of cooking fire statistics; and the evaluation of currently available technologies using this methodology. The project culminated with a one day workshop of 35 leaders from the kitchen appliance, fire service, and user communities who met to review the above findings and identify gaps in information. The highest priority action item identified at that workshop toward implementation of commercially available cooking fire mitigation technologies was:

“Develop standard fire scenarios and create test methods and performance criteria which can feed into standards development"

This report presents the results of a follow on project to gather data towards this goal.

The content, opinions and conclusions contained in this report are solely those of the authors.

\section{About the Fire Protection Research Foundation}

The Fire Protection Research Foundation plans, manages, and communicates research on a broad range of fire safety issues in collaboration with scientists and laboratories around the world. The Foundation is an affiliate of NFPA.

\section{About the National Fire Protection Association (NFPA)}

NFPA is a worldwide leader in fire, electrical, building, and life safety. The mission of the international nonprofit organization founded in 1896 is to reduce the worldwide burden of fire and other hazards on the quality of life by providing and advocating consensus codes and standards, research, training, and education. NFPA develops more than 300 codes and standards to minimize the possibility and effects of fire and other hazards. All NFPA codes and standards can be viewed at no cost at www.nfpa.org/freeaccess.

Keywords: Cooking fire scenarios; fire test methods; cooking oil fires; detection; temperature sensors 


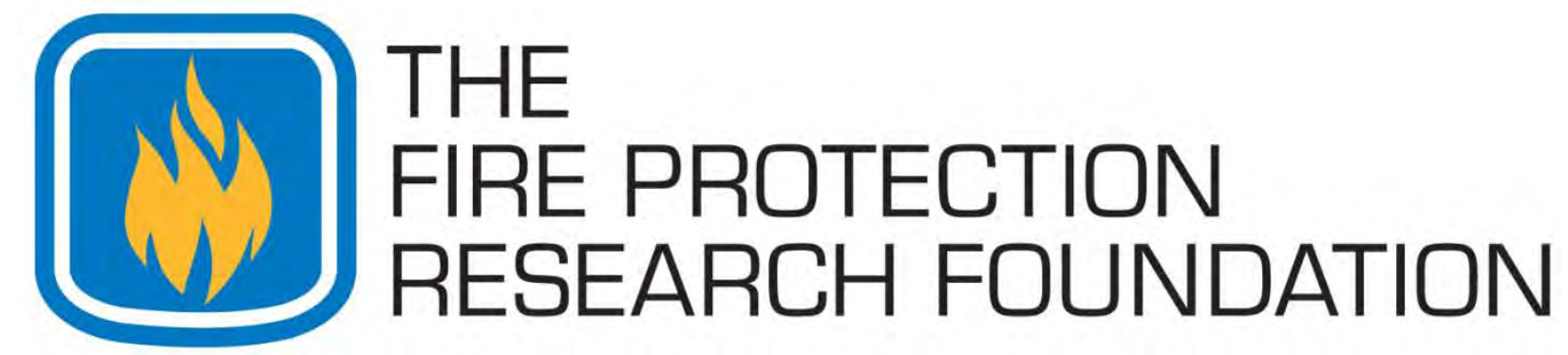

Technologies to Mitigate Home Cooking Fires

Project Steering Team

Jason Averill, NIST

Tom Fabian, Underwriters Laboratories

Andrew Trotta, CPSC

John Hall, NFPA

Marty Ahrens, NFPA

Pat Boyer, State Farm Insurance

Amanda Robbins, BRANZ

Wayne Morris, AHAM

Mike Love, Vision 20/20

The Fire Protection Research Foundation expresses gratitude to the Fire Grants Program of the National Institute of Standards and Technology for providing the funding for the project.

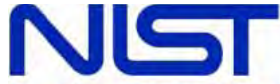

National Institute of

Standards and Technology

U.S. Department of Commerce 
Development of Standardized Cooking Fires

for Evaluation of Prevention Technologies: Phase One Data Analysis

\author{
Prepared for \\ Kathleen Almand \\ 1 Batterymarch Park \\ Quincy, MA 02169 \\ Prepared by \\ Joshua B. Dinaburg \\ Dr. Daniel T. Gottuk \\ Hughes Associates, Inc. \\ 3610 Commerce Dr. \\ Baltimore, MD 21227
}

National Fire Protection Research Foundation

October 14, 2013 


\section{TABLE OF CONTENTS}

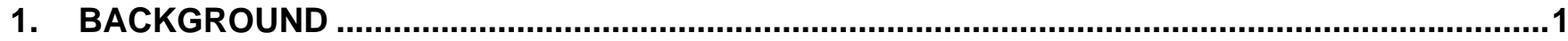

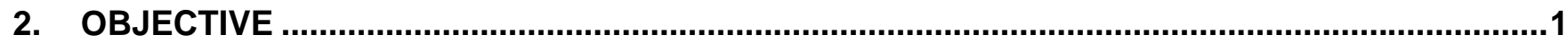

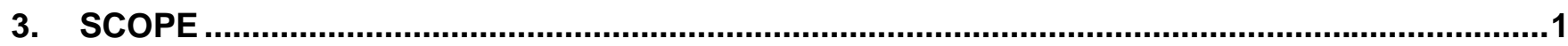

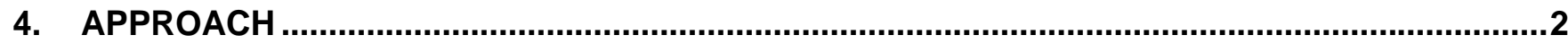

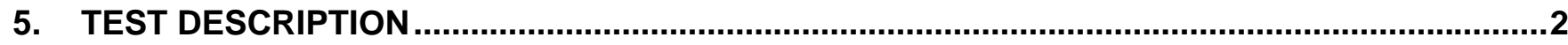

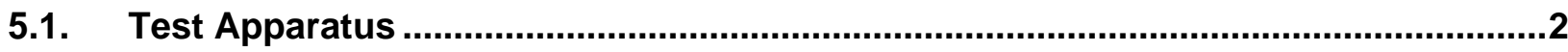

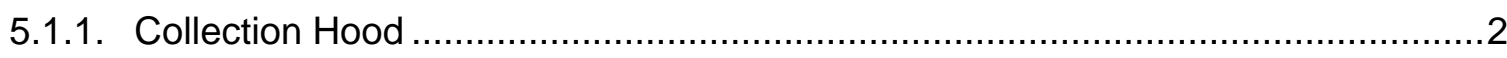

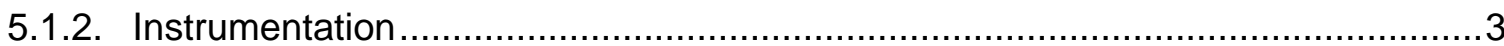

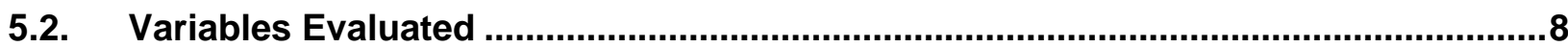

5.2.1. Ranges 8

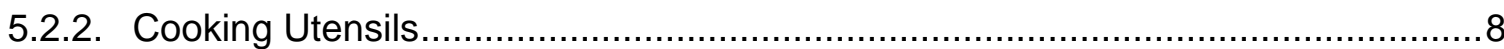

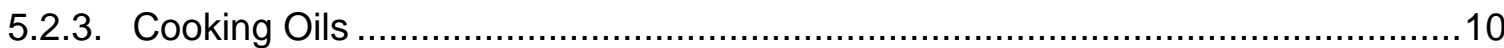

5.3. Measures of Performance .................................................................................11

5.3.1. Free Fatty Acid (FFA) Content .............................................................11

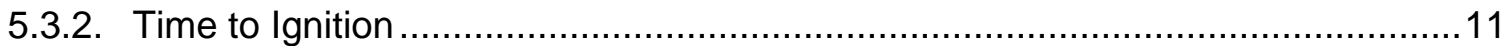

5.3.3. Smoke Measurement ........................................................................

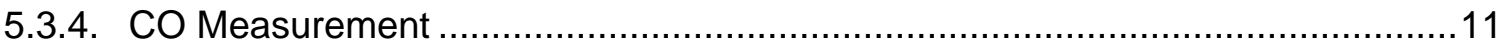

5.3.5. Conditions Approaching Ignition ............................................................. 12

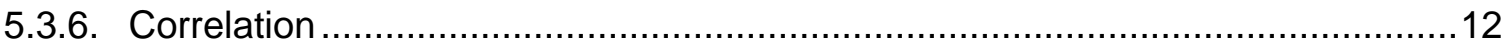

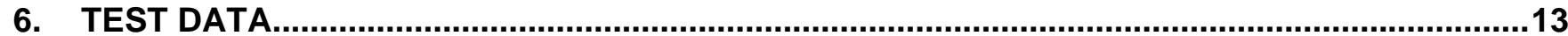

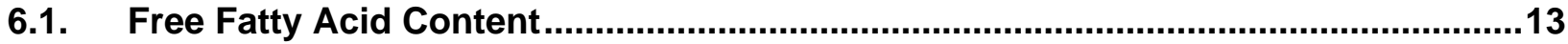

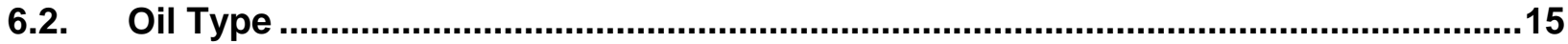

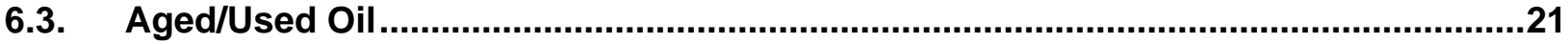

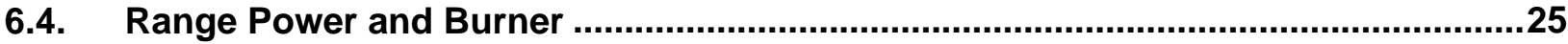

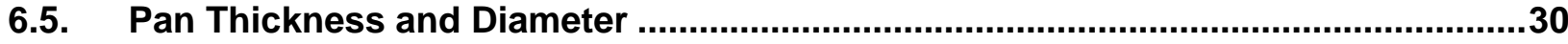

6.6. Pan Warping and Temperature Overshoot ..............................................................36

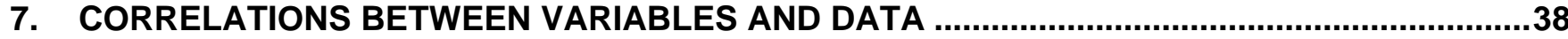

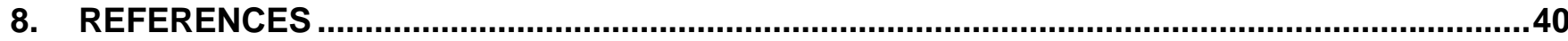




\section{BACKGROUND}

Cooking-equipment related fires are a leading cause of U.S. fire loss. The National Fire Protection Association (NFPA) reports that in 2006-2010, there were 157,300 reported home cooking related fires per year (42\% of all reported home fires), with associated annual losses of 380 civilian deaths (15\% of home fire deaths), 4,920 civilian injuries (38\% of home fire injuries), and $\$ 794$ million in direct property damage (11\% of home fire damages). Fires involving range tops accounted for $58 \%$ of these cooking equipment fire incidents and $87 \%$ and $76 \%$ of the deaths and injuries, respectively [1].

Beginning in the mid 1980's, the National Institute of Standards and Technology (NIST), Consumer Product Safety Commission (CPSC), and the home appliance industry undertook a comprehensive review of strategies to mitigate death, injury and property loss from cooking fires. All approaches were engineering strategies defined by a condition to be detected (e.g., overheat of pan or food in pan, absence of person actively engaged in cooking process, early-stage fire on stovetop) and an action to be taken (e.g., shut off cooking heat, sound alarm, suppress fire). As part of this study, a comprehensive review of existing technologies was done [2].

In February of 2010, a Vision 20/20 workshop on this topic was convened in Washington D.C. Participants recommended that a study be undertaken to identify the barriers to the utilization of these technologies and to develop an action plan towards improving cooking fire safety.

In 2010, Hughes Associates, Inc. (HAI) conducted a study for the Fire Protection Research Foundation (FPRF) supported by NIST to develop this action plan [2]. The study focused particularly on prevention technologies suitable for use on or with home cooking appliances. and consisted of a literature and technology review; the development of an enhanced technology evaluation methodology based on an in-depth review of cooking fire statistics; and the evaluation of currently available technologies using this methodology. The project culminated with a one day workshop of 35 leaders from the kitchen appliance, fire service, and user communities who met to review the above findings and identify gaps in information. The highest priority action item identified at that workshop toward implementation of commercially available cooking fire mitigation technologies was:

"Develop standard fire scenarios and create test methods and performance criteria which can feed into standards development."

Toward this end, a NIST funded a project through the FPRF and conducted by HAI, consisting of a series of tests evaluating various cooking fire scenarios (Phase 1). A wide array of cooking fire ignition data was collected during these tests in order to address the action item prioritized by the workshop. The approach, design and results from these tests are presented in this report.

\section{OBJECTIVE}

The primary objectives of the project are to:

1. Develop standardized tests for evaluation of range top cooking fire prevention technologies.

2. Develop performance criteria for conducting valid tests in accordance with the standard.

3. Develop performance criteria for assessing the fire protection performance of prevention technologies tested to the standard.

\section{SCOPE}

The scope of the phase 1 work was limited to developing fire scenarios for open coil electric range tops. This project was also limited to developing tests that evaluate automatic fire prevention technologies for 
use on cooking range tops. Devices utilizing suppression, notification, user intervention, flame containment, etc., were not considered in the test development.

Tests evaluated a range of potential ignition scenarios, including ranges, cooking utensils, and oil types. It is the intent to use this test data to select standardized scenarios based on repeatability, ignition properties, and applicability to prevention technologies. Additional testing has been planned (phase 2) in order to validate the repeatability and uncertainty of the existing test data as well as to evaluate additional test variables. The current data set is not considered sufficient to recommend standardized tests or develop performance criteria. This initial report is intend to present the current data for review, and a subsequent report will utilize the completed data sets to meet the objectives of the project.

\section{APPROACH}

Full scale testing was conducted using commercial range tops and cookware. Testing included the heating of various animal fats and plant derived oil types to the point of flaming ignition. The term oil generally refers to any viscous liquid that is immiscible with water. In this report, the term oil is used to refer to any fat derived from a plant or animal that is used in cooking. This includes fats that are generally solid at room temperatures, including pork lard or beef shortening. Pure oils were used with no solid food or actual cooking conducted. The oils were characterized by testing the free fatty acid (FFA) content. This oil property had been previously identified to correlate to the temperature of smoke production and ignition [3].

The temperatures of the pans, oils, and air, as well as the smoke and gas emissions were measured during heating to the point of ignition. This data is to be used to identify the conditions leading up to ignitions that may present the greatest challenges for initiation of automatic prevention devices. The most challenging scenarios would then be selected for use in standardized evaluation testing. The conditions leading up to ignition would also be used to identify performance criteria for evaluating devices subjected to the standardized testing.

The impact of several factors on ignition conditions were assessed during testing. Variables included:

1. Range power and coil design

2. Pan size and thickness

3. Pan flatness

4. Cooking oil type

5. Cooking oil age/usage

\section{TEST DESCRIPTION}

\subsection{Test Apparatus}

A cooking fire test apparatus was constructed in the HAI laboratory in Baltimore, MD. The apparatus consisted of an open coil electric cooking range placed beneath a collection hood in a test room that could be exhausted. Pans were instrumented to measure temperature of the pan and the oil. The smoke and gases emitted by the heated oil was collected and measured inside the hood above the range.

\subsubsection{Collection Hood}

Testing was conducted with a range placed beneath a $4 \mathrm{ft} \times 4 \mathrm{ft} \times 1 \mathrm{ft}(1.2 \times 1.2 \times 0.3 \mathrm{~m})$ deep sheet metal collection hood. The hood was centered above the tested pan and located $3 \mathrm{ft}(0.9 \mathrm{~m})$ above the 
surface of the range. The collection hood did not have any duct work or mechanical means for removing the products of combustion. By eliminating a forced air flow duct connected to the hood, the fire effluent measurements are not dependent on the flow rate through the duct; hence, this should lead to a higher degree of reproducibility from test to test and lab to lab.

The collection hood setup is shown in Figure 1. The effluent from the heated pan collected in the hood, creating a smoke layer that descended lower in the hood over time. When the layer descended below the $1 \mathrm{ft}(0.3 \mathrm{~m})$ depth of the hood, it spilled directly in to an open, ventilated space to remove the products of combustion from the test area. The open space was a $16 \mathrm{ft} \times 16 \mathrm{ft} \times 12 \mathrm{ft}(4.9 \times 4.9 \times 3.7$ $\mathrm{m})$ high room with a $1 \times 1 \mathrm{ft}(0.3 \times 0.3 \mathrm{~m})$ exhaust opening drawing approximately $600 \mathrm{ft}^{3} / \mathrm{min}$ $\left(17 \mathrm{~m}^{3} / \mathrm{min}\right)$ of air.

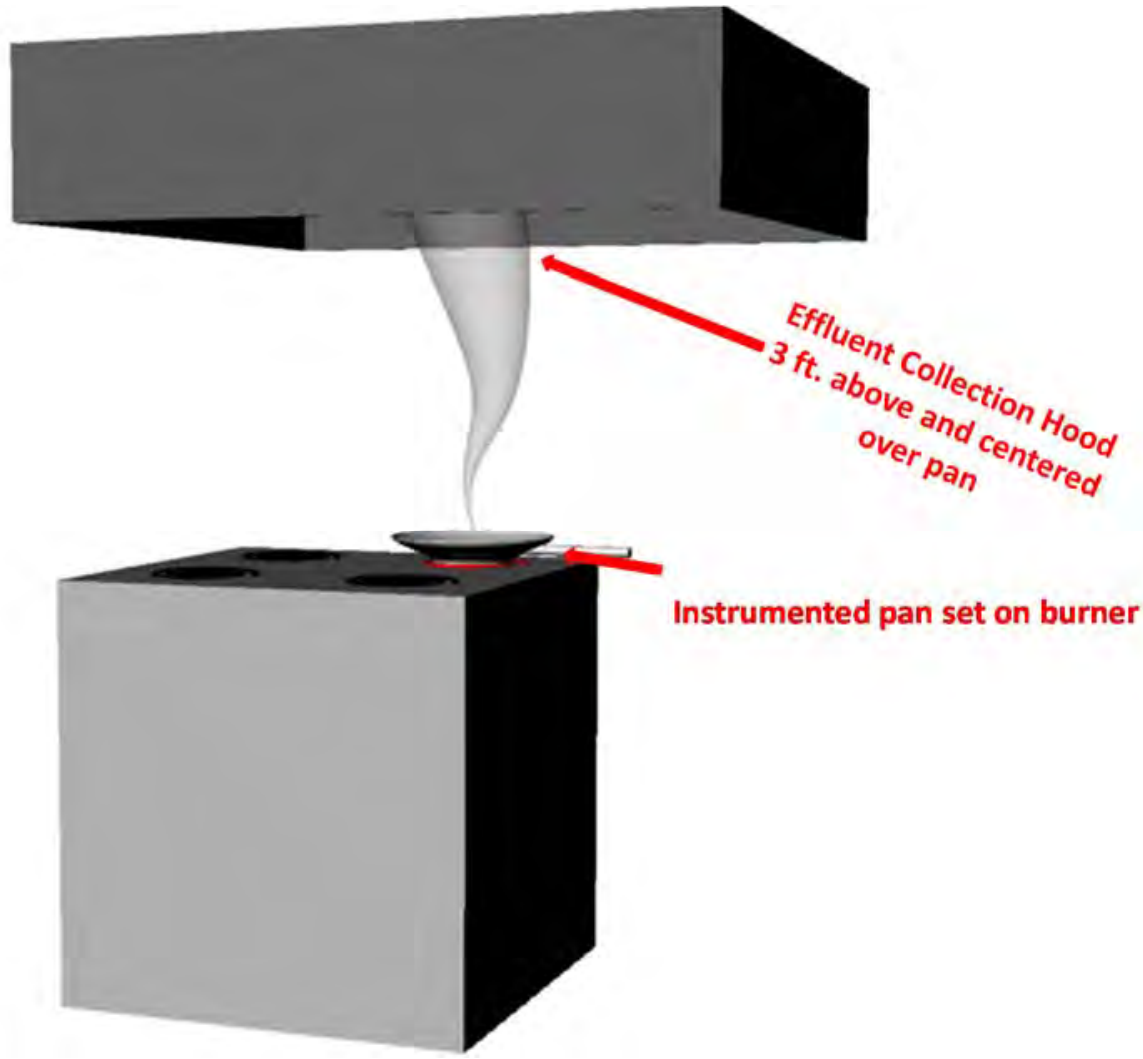

Figure 1 - Collection hood and range setup.

\subsubsection{Instrumentation}

Continuous temperature and voltage measurements were recorded during testing by a National Instruments cDAQ-9174 compact data acquisition chassis. Temperatures were measured using a cDAQ-9214 thermocouple module and voltages were measured using a cDAQ-9205 $\pm 10 \mathrm{~V}$ voltage module. Data was recorded by a Labview program at a rate of $1 \mathrm{~Hz}$ during fire tests.

\subsubsection{Range Power}

The range power was measured by continuous current measurement during fire testing. The voltage supplied to the range under test was measured prior to testing using an Omega multi-meter. The current was measured continuously by an Eaton EACP1420120SP AC current sensor. The voltage and current were multiplied to determine the wattage draw of the burner during testing. 


\subsubsection{Pan Temperature}

Pan temperatures were measured continuously during fire tests using 24 gauge fiberglass sheathed type $\mathrm{K}$ thermocouples welded to the top surface of the pan. Beads were welded at the ends of the wires by a TIGTECH 116SRL thermocouple welder with argon purge. The beads were then attached to the pan surface using a DCC Corporation HotSpot TC Welder.

Three thermocouples were placed in each pan tested at the center and along an axis with the handle, located 1 in. $(2.5 \mathrm{~cm})$ from the outside of the pan base. The pan thermocouple locations are shown in Figure 2.

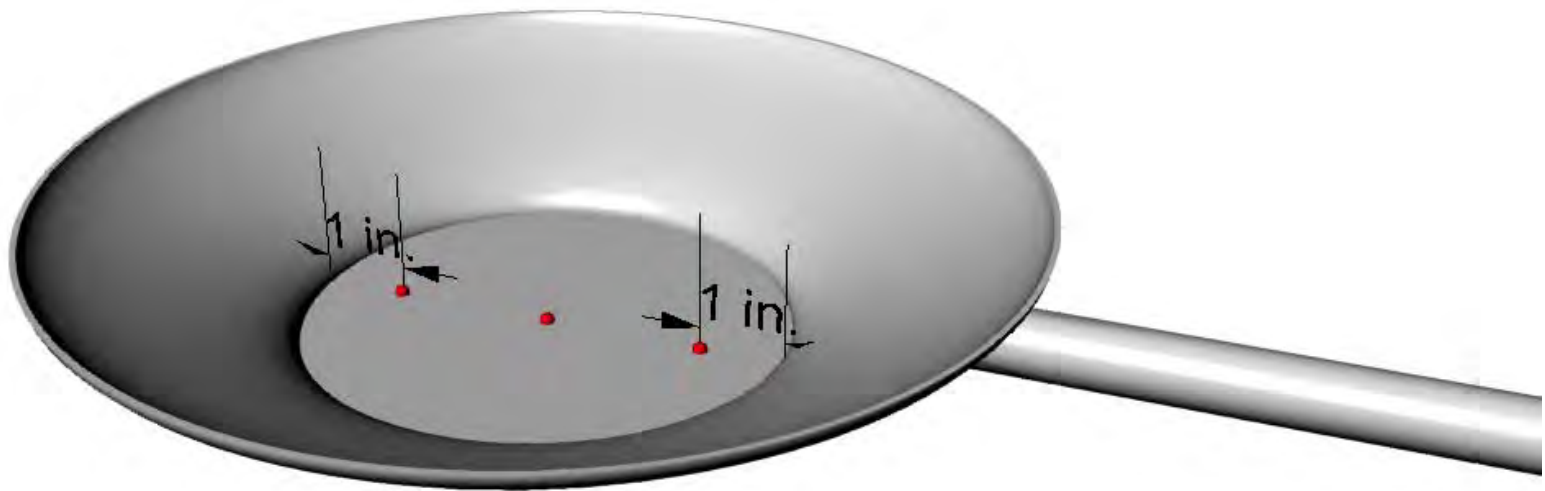

Figure 2 - Pan thermocouple measurement locations.

\subsubsection{Oil Temperature}

Oil temperatures were measured continuously using 24 gauge fiberglass sheathed type $\mathrm{K}$ thermocouples with welded beads. Beads were welded at the ends of the wires by a TIGTECH 116SRL thermocouple welder with argon purge.

The oil temperature measurement locations are shown in Figure 3. Nine thermocouples were placed in each pan at three locations each at three depths. The oil temperatures were measured at three locations along an axis perpendicular to the pan handle located $3 / 4$ of the pan base from the handle. The temperature was measured along the center line of the pan and $1 / 3$ of the pan diameter to either side of the center axis. At each location, the oil temperature was measured at half the depth of the oil, or 1/8 in. (3 mm). Additional measurements were made at each location 1/32 in. $(0.8 \mathrm{~mm})$ above and below half the oil depth (3/32 and $5 / 32 \mathrm{in.}(2.4 \mathrm{~mm}$ and $4.0 \mathrm{~mm})$ ). The additional measurements were conducted to assess the sensitivity of the measured oil temperature to the thermocouple depth in order to properly specify a standard test setup. 


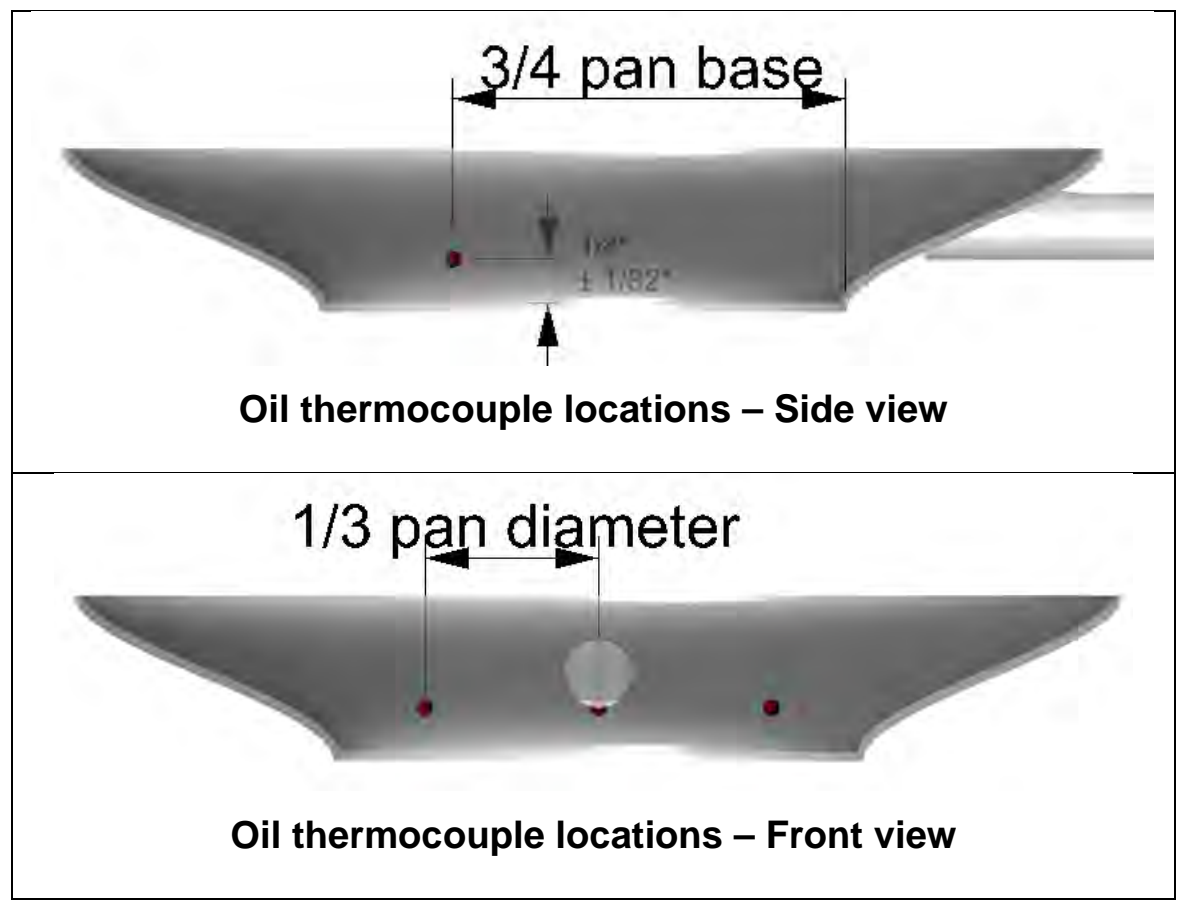

Figure 3 - Oil temperature measurement locations.

The oil thermocouple beads were held in place by clamping the wires between two aluminum bars resting on angled feet inside the pan. The two clamping bars were cut to a length $2 \mathrm{in.}(5.1 \mathrm{~cm})$ shorter than the pan diameter. The feet consisted of two pieces of $1 / 4 \mathrm{in}$. $(6.4 \mathrm{~mm})$ thick aluminum angle cut to $1 / 4$ in. $(6.4 \mathrm{~mm})$ widths. The two clamping bars were then screwed to the feet such that the bottom of the bars sat $1 / 4$ in. in. $(6.4 \mathrm{~mm})$ above the base of the feet. This provided a fill line to ensure $1 / 4$ in. $(6.4$ $\mathrm{mm}$ ) of oil had been used in each test and kept the thermal mass of the bars outside of the tested oil. The thermocouple wires were run between the two bars and the screws were tightened to keep the beads in place. Photographs of a pan with the aluminum mounting bars and the pan thermocouples, including a close up view of the mounting bar are shown in Figure 4.

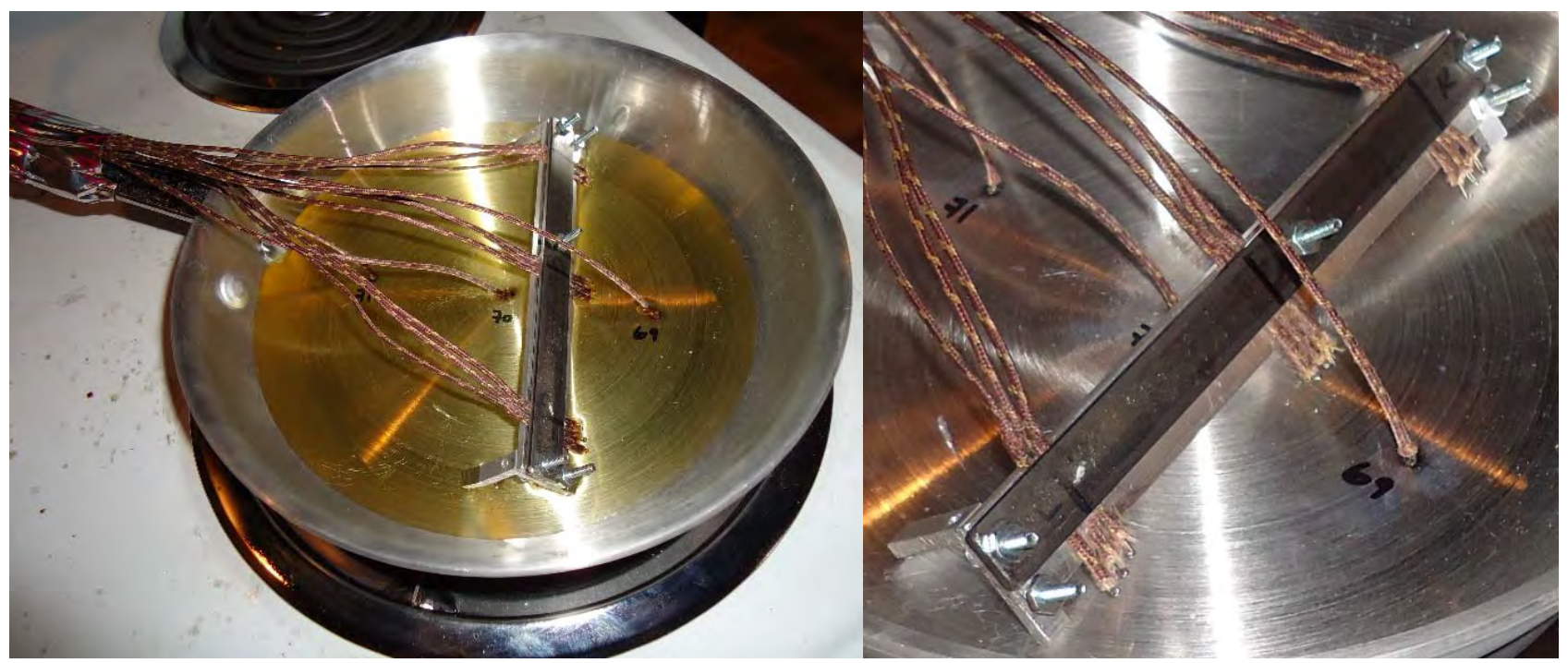

Figure 4 - Thermocouple measurements and mounting bar in test pan. 


\subsubsection{Effluent Temperature}

The temperature of the effluent rising off the pan during heating was measured using 24 gauge fiberglass sheathed type $\mathrm{K}$ thermocouples with welded beads. Beads were welded at the ends of the wires by a TIGTECH 116SRL thermocouple welder with argon purge.

Four thermocouples were used to measure the effluent temperature. They were located uniformly spaced in the collection hood 2 in. $(5.1 \mathrm{~cm})$ below the top of the hood. The thermocouples were each located in the center of a quadrant of the hood, located $12 \mathrm{in.}(30 \mathrm{~cm})$ from the walls and $24 \mathrm{in} .(61 \mathrm{~cm})$ from the adjacent thermocouples. The effluent thermocouple locations are shown with the smoke and gas concentration measurements in the hood diagram in Figure 5.

\subsubsection{Smoke Concentration}

Smoke concentrations were measured in the collection hood through laser light extinction measurements. Two ThorLabs CPS186, $670 \mathrm{~nm}, 4.5 \mathrm{~mW}$ lasers were mounted to the outside of the collection hood pointing down parallel axes $3 \mathrm{in} .(7.6 \mathrm{~cm})$ below the top of the hood and $12 \mathrm{in}$. $(30 \mathrm{~cm})$ from either side. The laser beam paths and installation locations are shown in Figure 5 . The lasers were powered by an EPSCO Model D-612T Filtered DC Power Supply at a constant $5 \mathrm{~V}$. The laser intensity was measured on the opposite side of the collection hood by PDA36A amplified SI photodiode detectors with variable gain and sensitivity to 350-1100 nm light. The smoke concentration was recorded as both optical density and obscuration per foot by comparing the intensity of laser light on the photodiodes prior to and during fire testing. The lasers viewed over a path length across the hood of $4 \mathrm{ft}$ $(1.2 \mathrm{~m})$.For this reason, the measured signal strength was reduced to zero at obscurations above $25 \% / \mathrm{ft}(82 \% / \mathrm{m})$, and no measurements greater than this level could be obtained.

The operation of the laser obscuration meters were verified using ThorLabs NG11 Schott Glass neutral density filters. The filters were placed in the beam path and the resulting obscurations and optical densities were calculated and confirmed. The lasers were verified using filters with optical densities at $670 \mathrm{~nm}$ of $0.112,0.298,0.374,0.945,1.838$, and 2.732 .

\subsubsection{Gas Concentrations}

Gas concentrations, including oxygen $\left(\mathrm{O}_{2}\right)$, carbon dioxide $\left(\mathrm{CO}_{2}\right)$, and carbon monoxide (CO), were measured in the collection hood. Gas samples were drawn and mixed from four locations in the hood, at the center of each quadrant and a distance of $1 \mathrm{in} .(2.5 \mathrm{~cm})$ below the top of the hood as shown in Figure 5. The gas samples were analyzed for concentration by a Horiba VA-3000 paramagnetic oxygen analyzer, a Horiba VIA-510 infrared carbon dioxide analyzer, and a Rosemount Analytical Model 880A infrared carbon monoxide analyzer. Transport time delays were measured until $90 \%$ of known concentrations were reported using calibration gases introduced at the sampling ports. Transport times ( $\left.\mathrm{t}_{90}\right)$ between 45 and 60 seconds were measured and accounted for in the presented test data. 


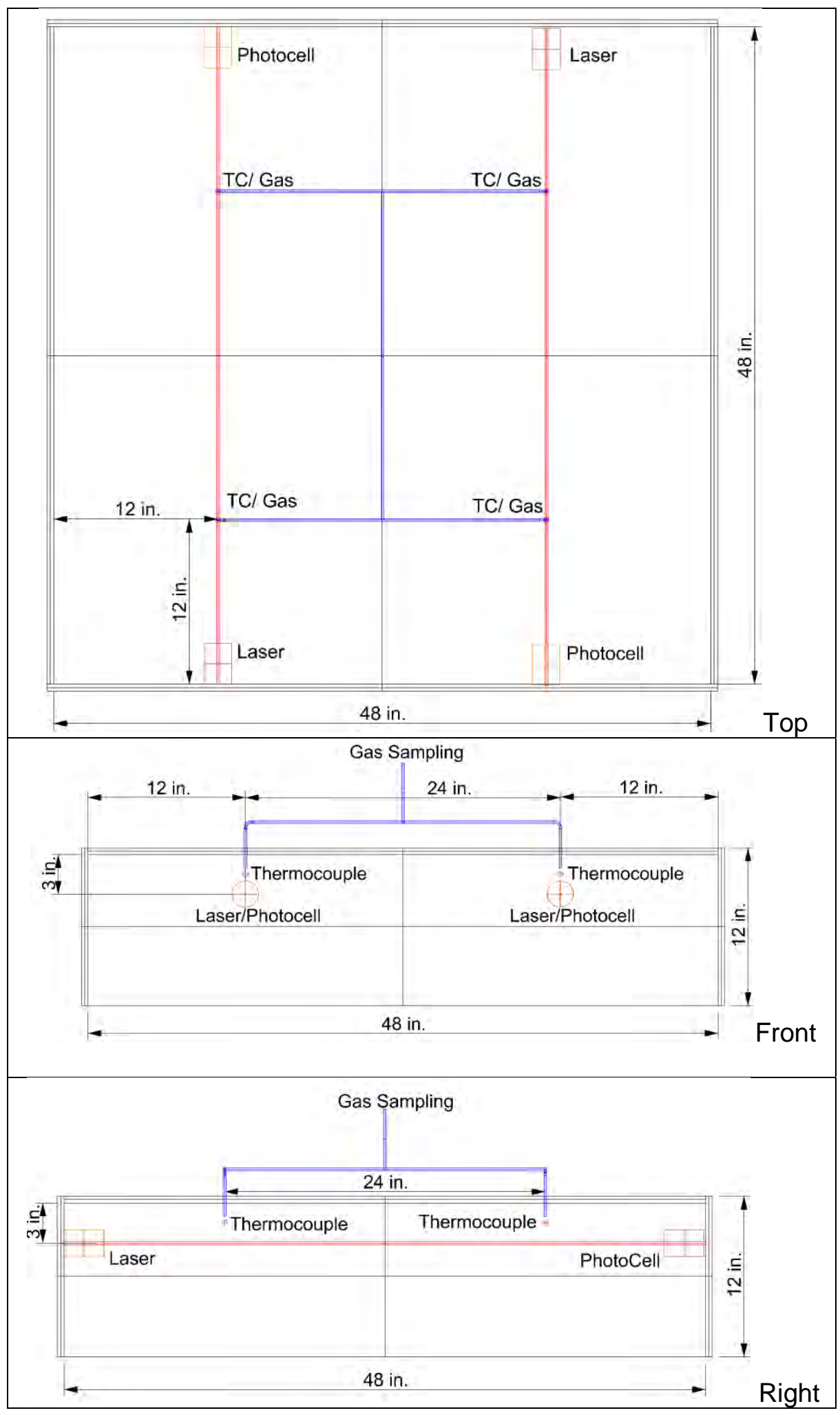

Figure 5 - Temperature, smoke, and gas measurements in the collection hood. 


\subsection{Variables Evaluated}

\subsubsection{Ranges}

Test fires were initiated using open coil electric range top heating elements. A GE JBP23DRWW and a Frigidaire FFEF3011 LW were selected for testing due to differences in heat output and burner coil surface area/shape. Tests were conducted on the 8 in. $(20 \mathrm{~cm}), 2600 \mathrm{~W}, 6$ turn coil and the 6 in. (15 $\mathrm{cm}), 1500 \mathrm{~W}, 4$ turn coil on the GE range. Tests were also conducted on the $8 \mathrm{in}$. $(20 \mathrm{~cm}), 2100 \mathrm{~W}, 4$ turn coil on the Frigidaire range. Tests were conducted with the burner power turned on to the highest setting, except for several tests conducted on the 8 in. $(20 \mathrm{~cm}) \mathrm{GE}$ burner where the power was matched to the $2100 \mathrm{~W}$ of the Frigidaire burner for direct comparison of the burner shape. The ranges and burners tested are shown in Figure 6.

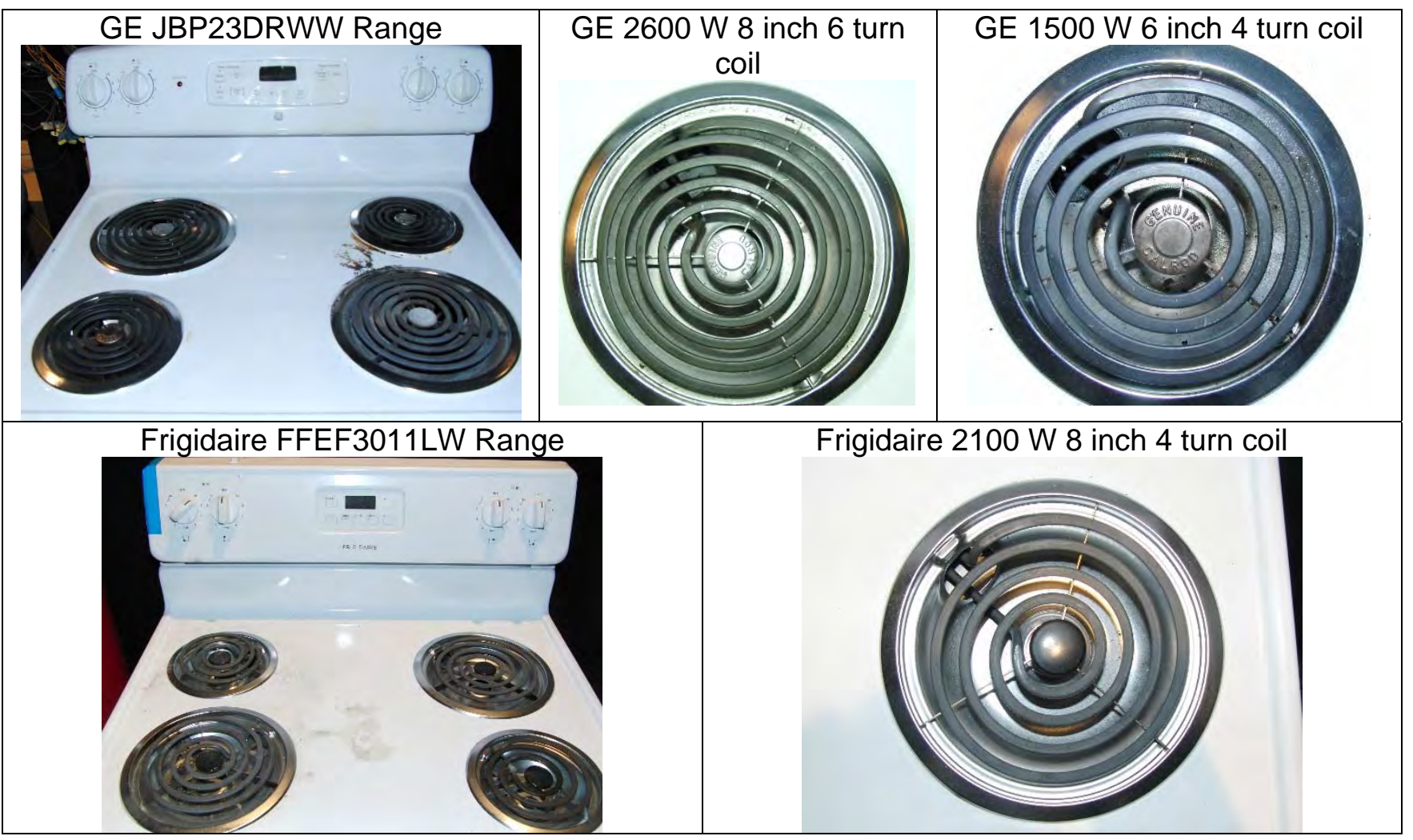

Figure 6 - Range tops and burners used during testing.

Both ranges required 240 VAC power. Power was provided by a variable control AC transformer set to provide $240 \mathrm{~V}$ to the ranges tested. The voltage was measured prior to the start of each test using a handheld voltmeter. The current drawn by the ranges was measured continuously during testing to determine the power output of the burners. When the power level on a burner was reduced from maximum, the power was observed to cycle on and off, and the numeric power setting was related to the duration of on-cycles. The power was reduced on the GE range by matching the burner on cycling time to the desired power ratio, in this case $2100 \mathrm{~W} / 2600 \mathrm{~W}$. Therefore, the burner power cycled on $81 \%$ of the time during the reduced power testing.

\subsubsection{Cooking Utensils}

Cookware used during testing included only solid aluminum fry pans of varying thicknesses (5-10 gauge) and diameters (7-14 in. (18-36 cm)). According to the Cookware Manufactures Association (CMA), aluminum pans represent the majority (approximately 70\%) of consumer products, and the selection of a single pan material allowed for evaluation of other variables that may impact ignition. For 
consistency and reproducibility, the evaluated pans were solid aluminum only and did not contain any non-stick coating and were not anodized. A summary of the pans tested is shown in Table 1. An example photograph of 8 gauge, $10 \mathrm{in.}(25 \mathrm{~cm})$ diameter pans is shown in Figure 7.

Table 1 - Aluminum Frying Pans Tested

\begin{tabular}{|c|c|c|c|c|c|c|c|c|}
\hline \multirow[b]{2}{*}{ Manufacturer } & \multirow[b]{2}{*}{ Brand } & \multirow[b]{2}{*}{ Model } & \multirow[b]{2}{*}{ Gauge } & \multirow{2}{*}{$\begin{array}{l}\text { Thickness } \\
\text { (in.) }\end{array}$} & \multicolumn{2}{|c|}{ Diameter } & \multicolumn{2}{|c|}{$\begin{array}{l}\text { Depth } \\
\text { (in.) }\end{array}$} \\
\hline & & & & & (in.) & $(\mathrm{cm})$ & (in.) & $(\mathrm{cm})$ \\
\hline \multirow{8}{*}{ Browne-Halco } & \multirow{8}{*}{ Thermalloy } & 14807 & \multirow{4}{*}{5} & \multirow{4}{*}{$\begin{array}{c}0.1819 \\
(4.6 \mathrm{~mm})\end{array}$} & 7 & 18 & 1.25 & 3.18 \\
\hline & & 14808 & & & 8 & 20 & 1.50 & 3.81 \\
\hline & & 14810 & & & 10 & 25 & 2.00 & 5.08 \\
\hline & & 14814 & & & 14 & 36 & 2.50 & 6.35 \\
\hline & & 13807 & \multirow{4}{*}{8} & \multirow{4}{*}{$\begin{array}{c}0.1285 \\
(3.3 \mathrm{~mm})\end{array}$} & 7 & 18 & 1.25 & 3.18 \\
\hline & & 13808 & & & 8 & 20 & 1.50 & 3.81 \\
\hline & & 13810 & & & 10 & 25 & 2.00 & 5.08 \\
\hline & & 13814 & & & 14 & 36 & 2.50 & 6.35 \\
\hline \multirow{7}{*}{ Vollrath } & Wear-Ever & 67907 & \multirow{3}{*}{8} & \multirow{3}{*}{$\begin{array}{c}0.1285 \\
(3.3 \mathrm{~mm})\end{array}$} & 7 & 18 & 1.75 & 4.44 \\
\hline & \multirow{2}{*}{ Arkadia } & 7010 & & & 10 & 25 & 1.75 & 4.44 \\
\hline & & 7014 & & & 14 & 36 & 2.50 & 6.35 \\
\hline & \multirow{4}{*}{ Wear-Ever } & 4007 & \multirow{4}{*}{10} & \multirow{4}{*}{$\begin{array}{c}0.1019 \\
(2.6 \mathrm{~mm})\end{array}$} & 7 & 18 & 1.50 & 3.81 \\
\hline & & 4008 & & & 8 & 20 & 1.88 & 4.76 \\
\hline & & 4010 & & & 10 & 25 & 2.00 & 5.08 \\
\hline & & 4014 & & & 14 & 36 & 2.50 & 6.35 \\
\hline
\end{tabular}

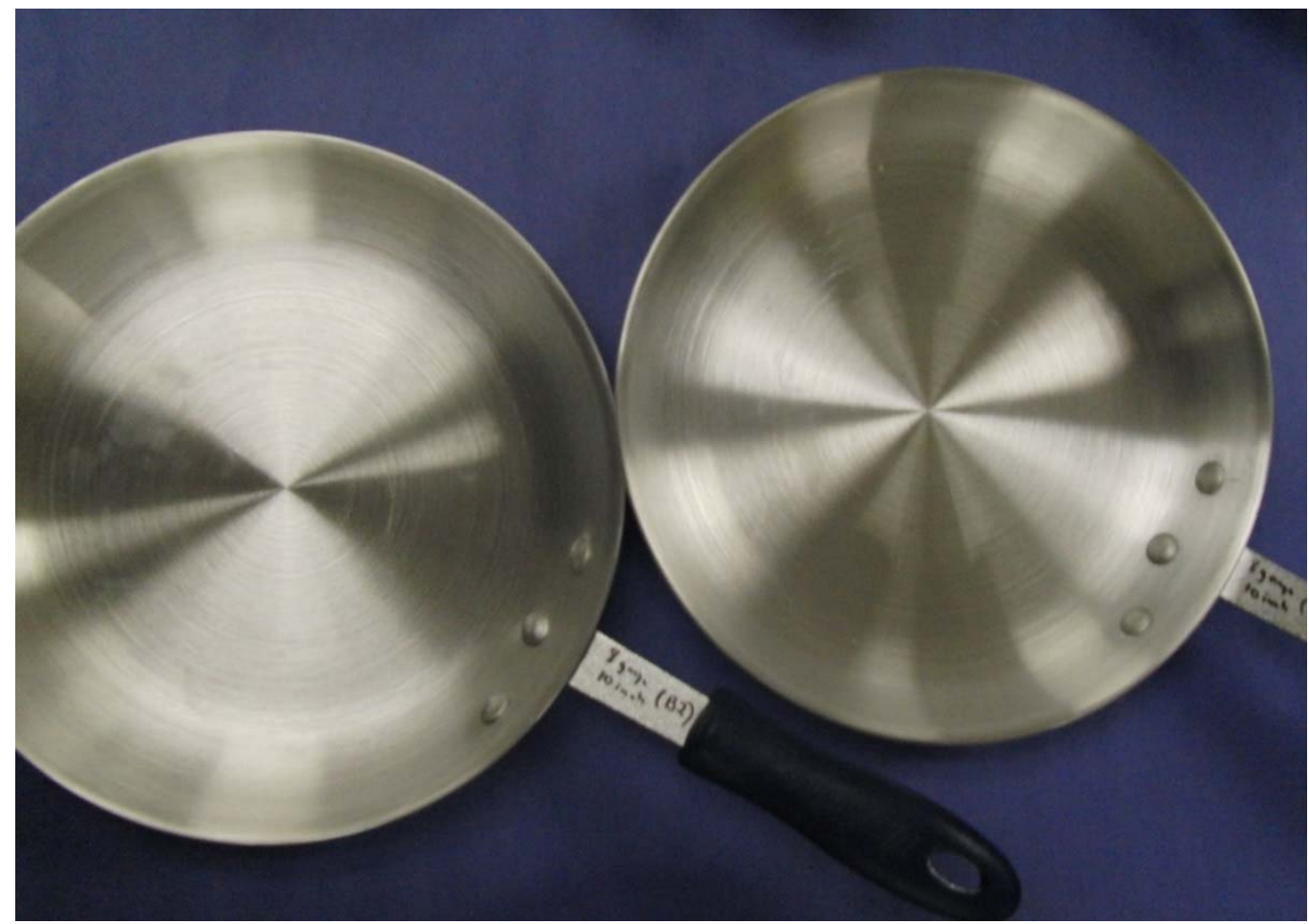

Figure 7 - Exemplar aluminum frying pans used during testing.

Cookware was only reused after a fire test if all solid material could be removed by cleaning and the flatness of the bottom of the pan remained within 0.006 times the pan diameter. This was considered the minimum amount of deviation in flatness that may impact test results. This level of flatness was selected in accordance with the flatness specifications included in UL 1026 41.2.9.1 [4]. The flatness 
was measured by placing a flat steel bar across the bottom of the pan and measuring the separation between the pan bottom and bar in three locations along two orthogonal axes. Measurements were made at the center and radial distances of $2 \mathrm{in}$. $(5.1 \mathrm{~cm})$. If the difference between any two of the six measurements exceeded 0.006 times the pan diameter, the pan was considered unacceptable. No pan was observed to exceed this allowance after repeated fire testing.

Additional testing was conducted to evaluate the ability to warp a pan using thermal cycling. A dry 10 gauge, 8 in. $(20 \mathrm{~cm})$ diameter pan was heated (with no contents) on the 8 in. $(20 \mathrm{~cm})$ GE burner until the pan temperature measured approximately $750^{\circ} \mathrm{F}-840^{\circ} \mathrm{F}\left(400^{\circ} \mathrm{C}-450^{\circ} \mathrm{C}\right)$. All power was then cutoff to the burner and the temperature overshoot was measured. When the temperature began to decrease it was dunked into a large water tank to initiate rapid cooling. This process was repeated through 30 heating and cooling cycles. The use of cookware with non-flat bottoms may impact the performance of a fire prevention device intended to make a contact temperature measurement with the bottom of the pan. In addition, these tests also quantified the degree of temperature overshoots that may occur after turning off the burner.

\subsubsection{Cooking Oils}

Tests were conducted using only pure cooking oils without solid food products. The intent of the overall project is to develop standardized testing, and the use of solid food would likely increase the variability and uncertainty in the test results (this issue will be evaluated in phase 2). Various formulations of cooking oils were used including both plant and animal fats. Commercial brand oils purchased from industrial suppliers were tested and compared to consumer brand (off the shelf) oils. Evaluated oils were selected from the most common cooking applications and included:

- Soybean (vegetable) oil

- Corn oil

- Canola oil

- Peanut oil

- Beef shortening

- Pork lard

The beef shortening and pork lard were solid fats at room temperatures. In order to pour the oils to a consistent depth for testing, these oils were preheated in a separate pot to a temperature of $95^{\circ} \mathrm{F}$ $\left(35^{\circ} \mathrm{C}\right)$ and melted. The liquids were then poured to a test depth of $1 / 4 \mathrm{in}$. $(6.4 \mathrm{~mm})$ and testing conducted without allowing the liquid to re-solidify.

Consumer brand oils tested included Wesson and Crisco brand soybean (vegetable) and canola oils. All oils subjected to fire tests were analyzed for the FFA content by an external testing laboratory. This component of cooking oil has been reported to be inversely correlated with the auto-ignition temperature and smoke point [3]. It was recommended by the American Oil Chemists' Society (AOCS) to use FFA to characterize the various oil types tested.

In order to evaluate the potential impacts of used oil on ignition parameters, the commercial oils tested were artificially "aged" by maintaining a pot of oil at $400^{\circ} \mathrm{F}\left(204^{\circ} \mathrm{C}\right)$ for a total of 8 continuous hours. Fire tests and FFA analyses were conducted on the aged oils to determine the potential impacts on ignition conditions. In addition to the artificially aged oils, a sample of used soybean (vegetable) oil was obtained from a fast food restaurant. The oil was used throughout lunchtime to cook french fries and chicken nuggets and was included to represent a scenario for heavily used oils. These tests were included due to concerns that residential cooking performed with used oils may present an increased hazard of ignition compared to cooking with fresh oil. This would present an additional challenge for a prevention device and was therefore considered for development of a standardized test. 
All fire tests were conducted by pouring $1 / 4$ in. $(6.4 \mathrm{~mm})$ of oil into each pan evaluated. This depth of oil was used to minimize test time and was found to produce consistent ignition in all tests while providing sufficient depth to allow for insertion of temperature probes into the oil without contacting the surface of the pan. No other oil depths were evaluated.

\subsection{Measures of Performance}

Data taken during testing provided transient growth profiles for temperature, smoke, and gas concentrations during heating and up to the point of flaming ignition. In addition to the temporal variations, spatial variations in temperature were measured on the pan surface, in the cooking oil, and in the effluent. Smoke concentrations were measured at two symmetric locations within the collection hood. This data has been processed and condensed to provide several measures of performance for each test conducted. These measures are intended to provide representative values for comparison of various test scenarios and to identify variability among repeat test scenarios.

\subsubsection{Free Fatty Acid (FFA) Content}

For each test conducted, the oil used was subjected to an FFA evaluation. The FFA has been reported to correlate to the auto-ignition temperature and smoke point. In addition to the presentation of the fire test data, the measured FFA content of the tested oils are reported.

\subsubsection{Time to Ignition}

The time to ignition is the total amount of time from powering the burner coil until flaming ignition occurred. Flaming ignition times were recorded through visual observation. This measure of performance provides an indication of how much thermal energy was required to initiate flaming fire for the pan/burner/oil tested.

\subsubsection{Smoke Measurement}

This measure of performance includes the additional heating time between a low level smoke measurement in the hood and ignition. Visual observations of smoke production were found to be extremely variable, and it was determined through observation of data that smoke measurements exceeded the noise and continued to rise until ignition when an average obscuration of $1.5 \% / \mathrm{ft}(5 \% / \mathrm{m})$ was measured between both lasers. When this condition had been met, the total remaining time until ignition has been reported. This time represents a quantitative evaluation of how much time remains until ignition after a relatively low level of smoke is produced. This method removes the subjectivity and uncertainty that occurs from evaluating first smoke based on a visual assessment of when smoke is noticeable to an observer. In addition to the remaining time, the average pan and oil temperatures at the time of early smoke measurement are reported. The averaged values reported include all spatial locations as well as data 3 seconds prior to and 3 seconds after each noted time.

\subsubsection{CO Measurement}

This measure of performance includes the additional heating time between a low level CO measurement in the hood and ignition. It was determined through observation of data that $\mathrm{CO}$ measurements generally exceeded noise and continued to rise when a value of $5 \mathrm{ppm}$ was measured. When this condition had been met for a set of test data, the total remaining time before ignition has been reported. In some tests, the threshold value of $\mathrm{CO}$ was not reached before ignition occurred, and this has been noted. This time represents a quantitative evaluation of how much time remains until ignition after a relatively low level of measureable CO is produced.

No consistent measurements of increased $\mathrm{CO}_{2}$ or reduced $\mathrm{O}_{2}$ concentrations were observed for the tests conducted. Some tests resulted in measureable changes to these concentrations, but the trends 
were not consistently observed between repeat tests, or due to any specific tested condition. No measure of performance using this data has been included in the analysis.

\subsubsection{Conditions Approaching Ignition}

In order to utilize the test data to develop performance criteria for prevention devices, a measure of the conditions leading up to ignition is necessary. In order to provide some margin of safety, a prevention device must actuate some time prior to ignition, rather than immediately before. The average smoke obscuration and pan and oil temperatures have been calculated at ignition as well as at 30,60, and 90 seconds before ignition occurred for each test. The temperatures have also been calculated at the time of the early measureable smoke concentration (Obs $=1.5 \% / \mathrm{ft}(5 \% / \mathrm{m})$ ). The averaged values reported include all spatial locations as well as data 3 seconds prior to and 3 seconds after each noted time. This temporal spread accounts for some error in the visually observed ignition time. The average of pan and oil temperatures and smoke concentration have been reported.

\subsubsection{Correlation}

The measure of correlation between the tested variables and the measurements have been calculated using the Pearson's correlation coefficient, $r_{x y}$. The correlation coefficient is calculated between two data sets by taking the means of the variable and data, and summing products of the differences between the data and the mean. This calculation is shown in Equation 1.

$$
r_{x y}=\frac{\sum_{i=1}^{n}\left(x_{i}-\bar{x}\right)\left(y_{i}-\bar{y}\right)}{\sqrt{\sum_{i=1}^{n}\left(x_{i}-\bar{x}\right)^{2}} \sum_{i=1}^{n}\left(y_{i}-\bar{y}\right)^{2}}
$$

The Pearson's correlation provides an estimate of the relationship between the tested variable, $x \mathrm{i}$, and the resulting measurement, $y_{\mathrm{i} \text {. }}$ The value of $r_{x y}$ can range from -1 to 1 , with values indicative of the relationships shown in Figure 8. These ranges are only relative and interpretative, and do not reflect defined rules for the Pearson's correlation.

The correlation between test variables and test measurements has been calculated to identify potential relationships. Evaluated variables include:

- The FFA of the tested oil;

- The power input of the burner to the pan;

- The thickness of the pan; and,

- The diameter of the pan.

The relationship between these variables and test measurements have been calculated. The test measurements evaluated for correlation include:

- The total heating time until ignition;

- The remaining heating time between a smoke measurement of $1.5 \% / \mathrm{ft}(5 \% / \mathrm{m})$ and ignition;

- The remaining heating time between a $\mathrm{CO}$ measurement of $5 \mathrm{ppm}$ and ignition;

- The pan and oil temperatures when a smoke measurement of $1 / 5 \% / \mathrm{ft}(5 \% / \mathrm{m})$ was made;

- The pan and oil temperatures at ignition;

- The difference between the pan and oil temperatures at ignition and the temperatures 30, 60 , and 90 seconds before ignition; and,

- The smoke obscuration 60 seconds before ignition. 


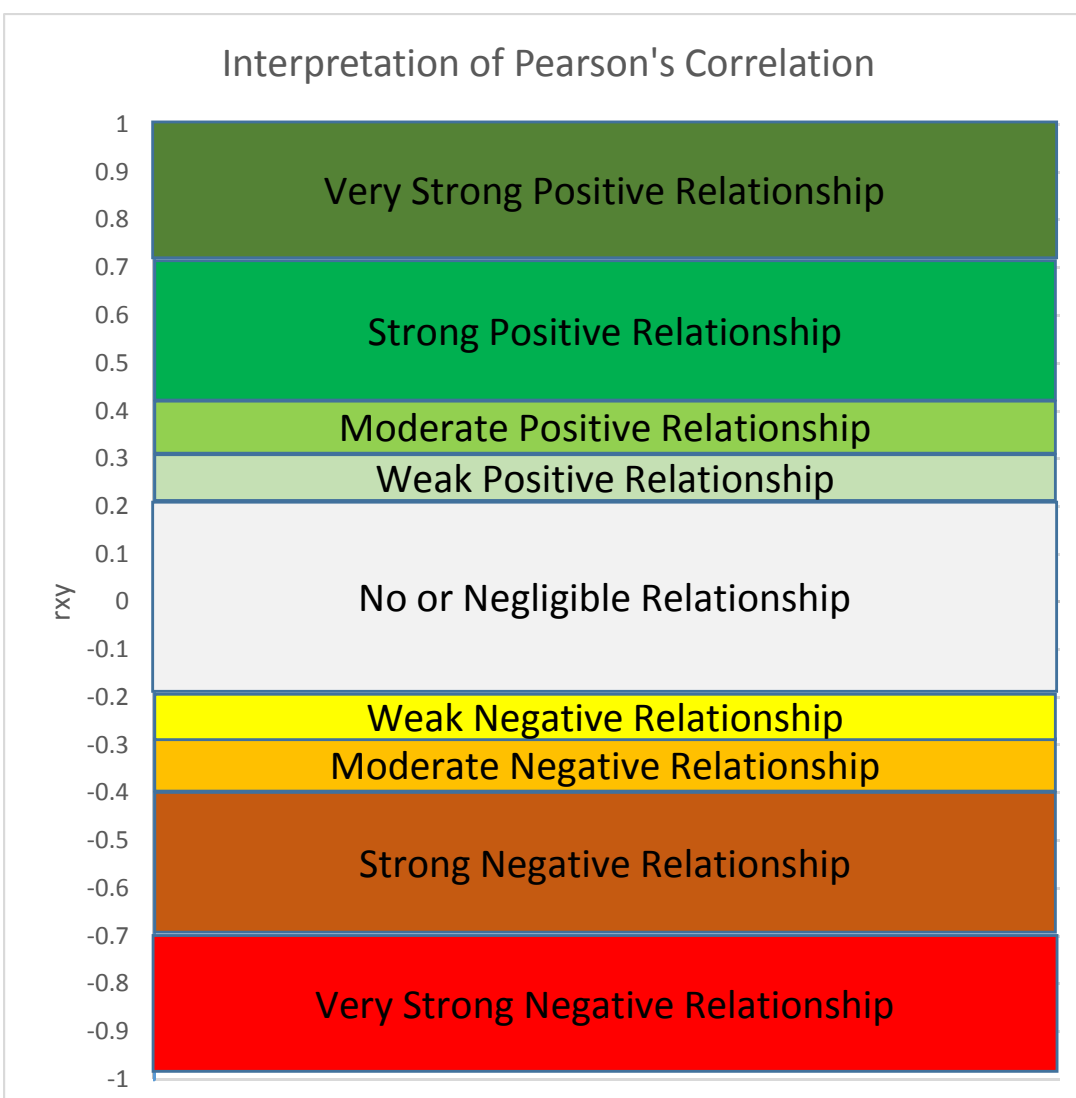

Figure 8 - Interpretation of Pearson's Correlation calculated for test data and variables.

6. TEST DATA

\subsection{Free Fatty Acid Content}

All evaluated oils were tested for the FFA content. Several of the oil samples were subjected to sustained heating in an attempt to simulate use and artificially increase the FFA. One other sample of oil was obtained after lunch time from the deep fryer of a fast food restaurant. The various oils subjected to fire testing and the measured FFA of each are shown in Table 2.

Table 2 - Free Fatty Acid Content of Tested Oils

\begin{tabular}{|c|c|c|}
\hline Oil Type & $\begin{array}{l}\text { New Oil FFA } \\
(\%)\end{array}$ & $\begin{array}{c}\text { Artificially Aged } 8 \text { hour FFA } \\
(\%)\end{array}$ \\
\hline Soybean Oil (Commercial) & 0.044 & 0.14 \\
\hline $\begin{array}{l}\text { Wesson Vegetable Oil } \\
\text { (Soybean) }\end{array}$ & 0.024 & \\
\hline Crisco Vegetable Oil & 0.023 & \\
\hline Used Fast Food Vegetable Oil (Soybean) & 4.4 & \\
\hline Canola Oil (Commercial) & 0.021 & 0.12 \\
\hline Wesson Canola Oil & 0.023 & \\
\hline Crisco Canola Oil & 0.020 & \\
\hline Corn Oil (Commercial) & 0.064 & 0.16 \\
\hline Peanut Oil (Commercial) & 0.021 & 0.035 \\
\hline Beef Shortening (Commercial) & 0.023 & 0.07 \\
\hline Pork Lard (Commercial) & 0.21 & 0.26 \\
\hline
\end{tabular}


The simulated aging process was observed to increase the FFA of the oils for all tested cases. The minimum resulting increase was observed for peanut oil, with an increase of $0.014 \% \mathrm{FFA}$, and the maximum increase in FFA was observed for both the soybean and corn oils, increasing by $0.096 \%$ FFA. The increase in the FFA due to sustained heating was less than observed for the oil used in a deep fryer for cooking, however, which reported 4.4\%FFA, an increase over the commercial soybean oil of two orders of magnitude.

Each of the oils were subjected to a baseline test, which included the use of an $8 \mathrm{in} .(20 \mathrm{~cm})$ diameter, 8 gauge aluminum pan placed on the $2600 \mathrm{~W}, 8 \mathrm{in} .(20 \mathrm{~cm})$ burner of the GE range on its highest setting. All tests used $1 / 4$ in. $(6.4 \mathrm{~mm})$ oil depth. The pan and oil temperatures when measureable smoke was observed and at ignition for these tests are shown in Figure 9 as a function of the FFA. The previously reported impact of FFA on heated oil smoke production and ignition are also shown in Figure 9 [3]. The reported data was obtained for observations of smoke and ignition of a droplet of oil placed onto a fixed temperature hotplate. The temperatures obtained for new test data are for the average pan and bulk oil temperatures when the lasers measured 1.5\%/ft $(5 \% / \mathrm{m})$ smoke obscuration or when the oil ignited, and are greater than the measured droplet temperatures from the previous data. In addition, the measured pan temperatures are greater than the average oil temperatures at each condition, as shown in the Figure.

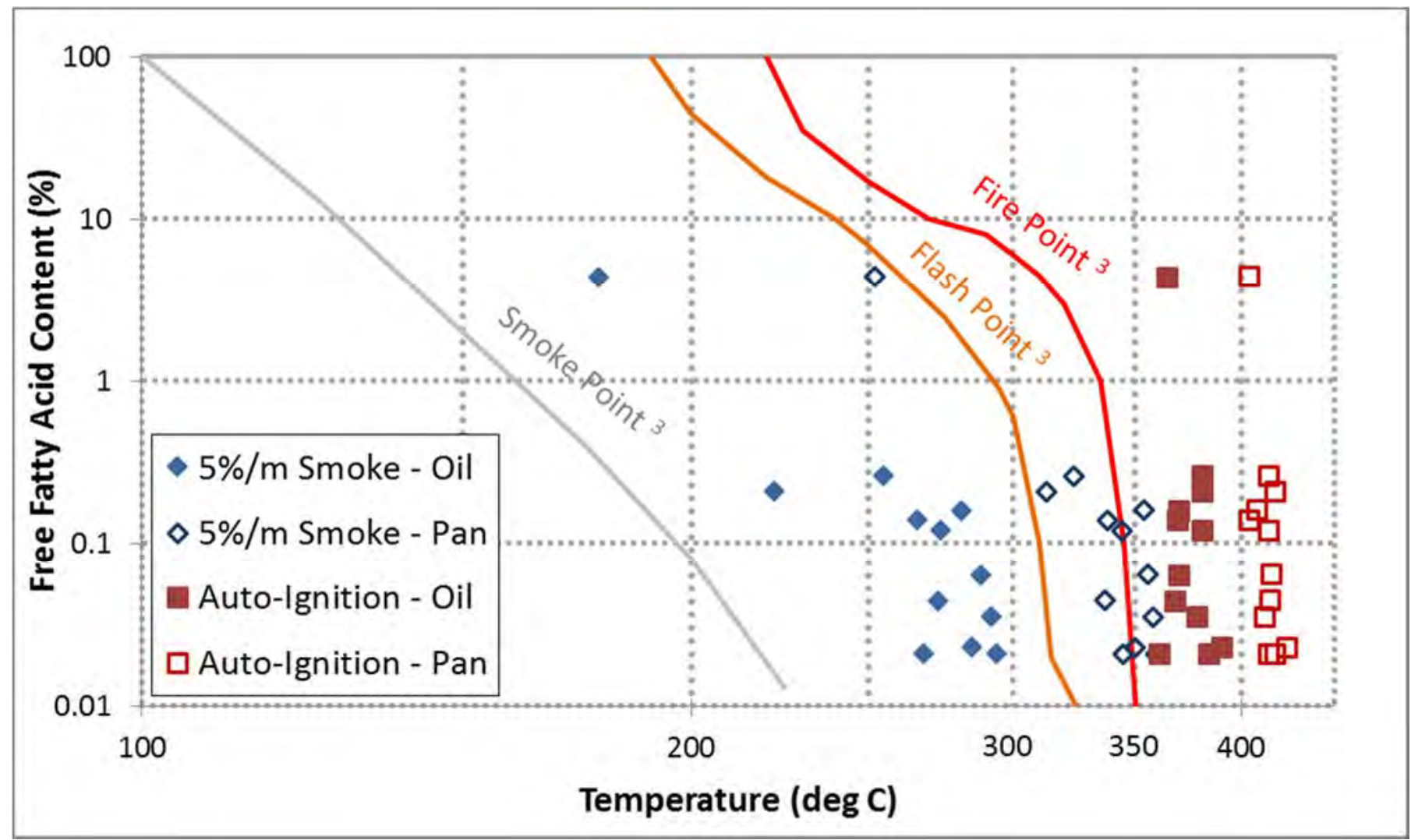

Figure 9 - Pan and oil temperatures at smoke measurement and ignition as a function of the FFA content of the tested oil (lines are from Ref 3 ). 


\subsection{Oil Type}

Fire tests were conducted on numerous types of oils, including soybean (vegetable), corn, canola, peanut, beef shortening, and pork lard. These commercial grade oils were obtained from an industrial supplier. In addition, Wesson and Crisco consumer brand soybean (vegetable) and canola oils were tested. All oil evaluation tests were conducted on the 8 in. $(20 \mathrm{~cm})$ burner of the $2600 \mathrm{~W}$ GE range, in an 8 in. $(20 \mathrm{~cm})$ diameter, 8 gauge aluminum frying pan. A total of $13.4 \mathrm{in}^{3}(220 \mathrm{~mL})$ of oil was used for each test, resulting in an initial oil depth of $1 / 4 \mathrm{in}$. $(6.4 \mathrm{~mm})$ The total heating times required to reach ignition are shown in Figure 10, with the oils ordered from lowest to highest percent FFA.

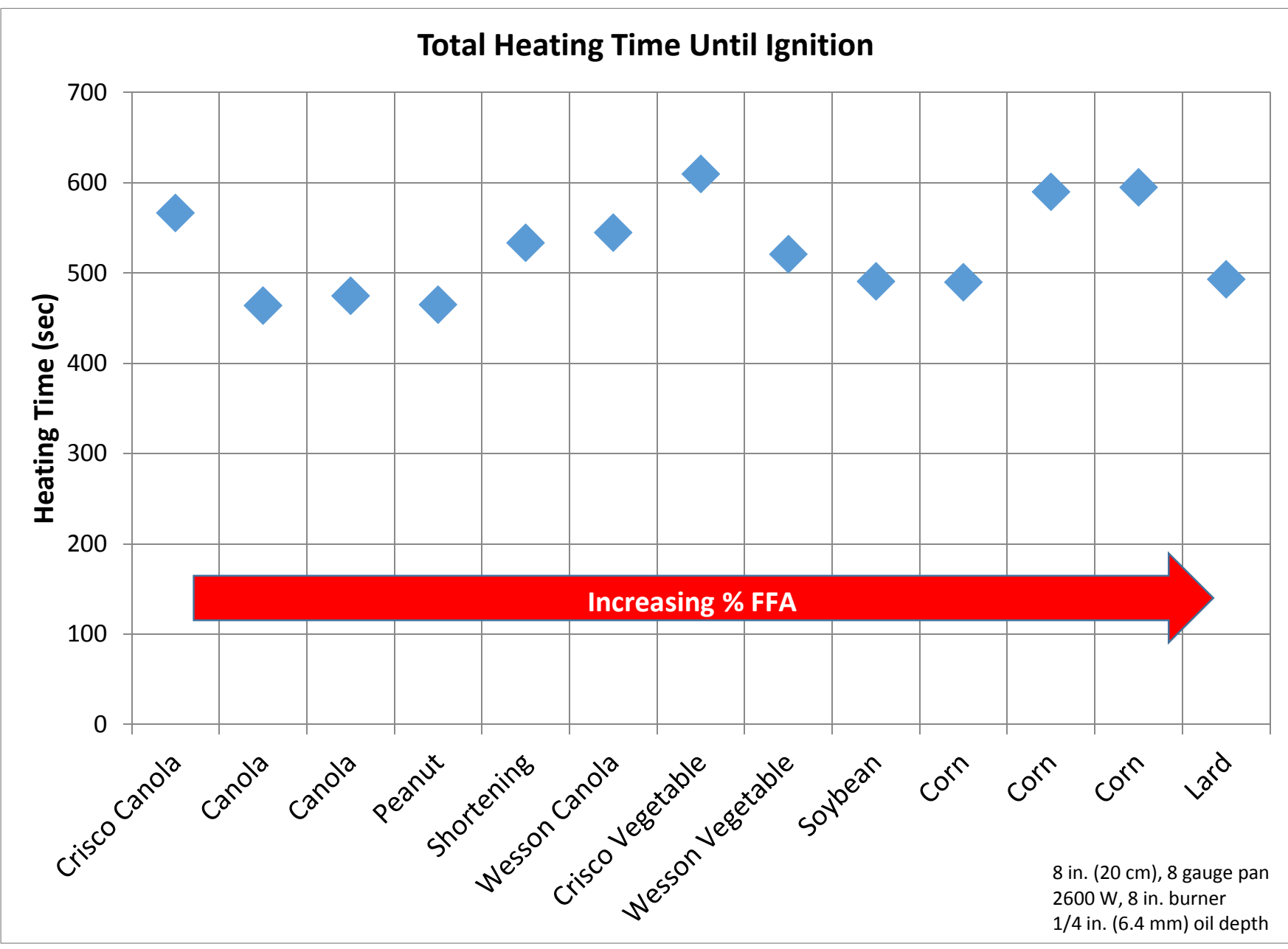
Figure 10 - Heating times until ignition for various oil types heated in an 8 in. $(20 \mathrm{~cm})$ diameter,
8 gauge aluminum frying pan.

The average heating time to ignition for all oils tested was 525 seconds ( 8.75 minutes). The shortest time to ignition was observed for one of two industrial canola oils tests, with the earliest ignition occurring after 464 seconds (7.7 minutes). The longest time to ignition occurred for the Crisco brand soybean (vegetable) oil after 610 seconds (10.2 minutes). Repeat corn oil test showed a range of 105 seconds among the three tests in the measured times to ignition. Repeat canola oil tests showed a range of 11 seconds among the two tests in the measured times to ignition. A correlation coefficient of -0.1 was calculated between the percent FFA of the oil and the time to ignition. This is considered a negligible relationship among the oils tested.

The remaining heating time between a smoke measurement of $1.5 \% / \mathrm{ft}(5 \% / \mathrm{m})$ and ignition for each tested oil are shown in Figure 11. Measurements of 1.5\%/ft (5\%/m) smoke in the collection hood were 
recorded between 124 seconds (2.1 minutes) and 306 seconds (5.1 minutes) before ignition occurred. The average time between this smoke measurement and ignition was 191 seconds (3.2 minutes). The shortest window between smoke and ignition was observed for peanut oil. The longest window between smoke and ignition was observed for Crisco soybean (vegetable) oil. Repeat corn oil tests showed a range from 130 to 239 seconds (2.2 to 4.0 minutes) in the measured times from $1.5 \% / f t$ $(5 \% / m)$ smoke to ignition. Repeat canola oil tests showed a range from 132 to 139 seconds (2.2 to 2.3 minutes) in the measured times from $1.5 \% / \mathrm{ft}(5 \% / \mathrm{m})$ smoke to ignition. A correlation coefficient of 0.0 was calculated between the percent FFA of the oil and the time between this low smoke measurement and ignition. This implies no relationship among the oils tested.

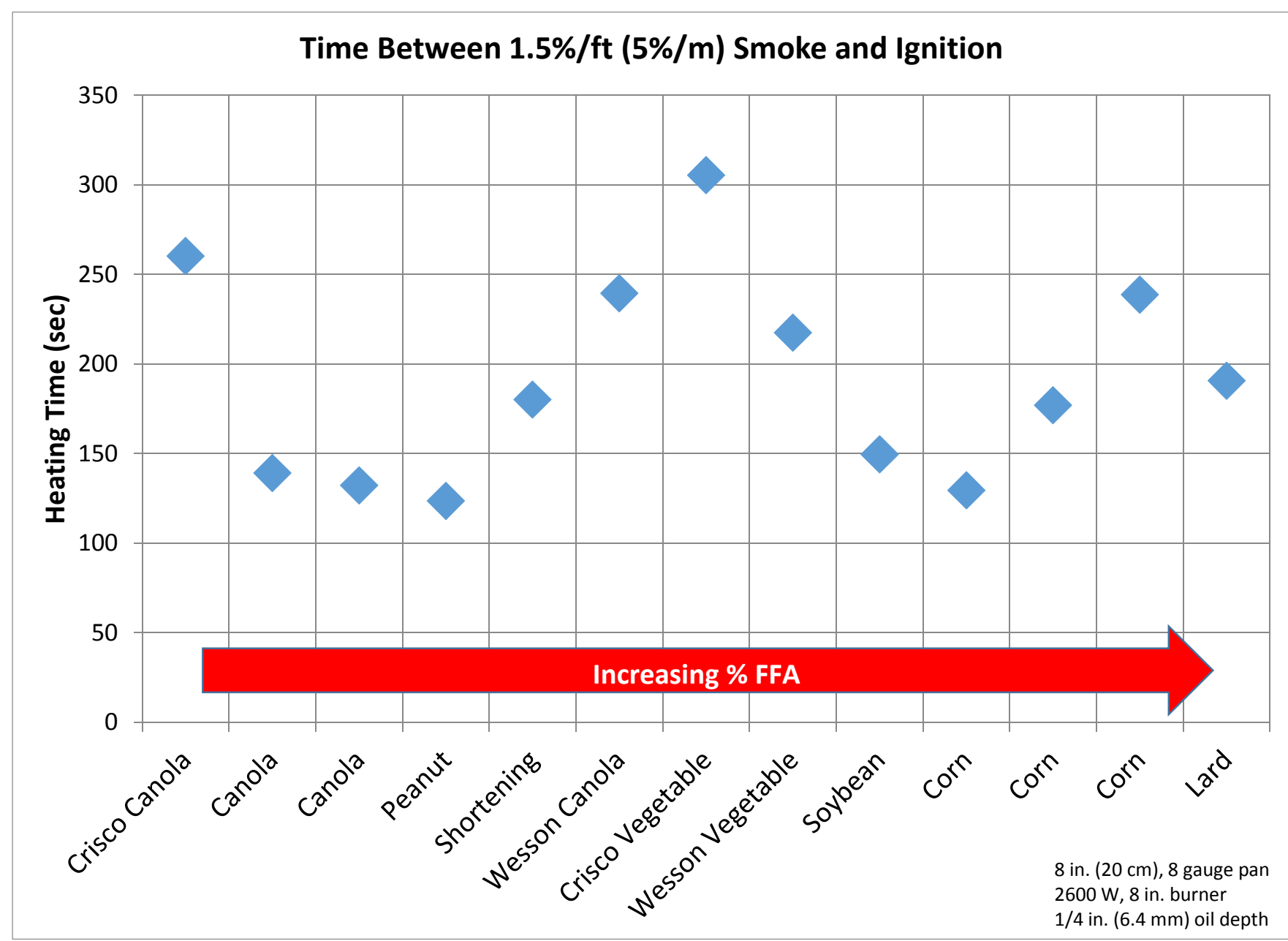

Figure 11 - Available time between 1.5\%ft (5\%/m) smoke measurement and ignition for various oils.

The time that initial CO measurements of $5 \mathrm{ppm}$ were made before ignition for each test are shown in Figure 12. Initial measurements of 5 ppm CO in the collection hood were recorded between 153 seconds ( 2.6 minutes) before ignition and 11 seconds ( 0.2 minutes) after ignition occurred. The average time between the low CO measurement and ignition was 44 seconds. In some tests, including the Crisco soybean (vegetable) oil, and Wesson canola oil, the measurement did not occur until after ignition. Repeat corn oil tests showed a range from 24 to 153 seconds ( 0.4 to 2.6 minutes) in the measured times from $5 \mathrm{ppm} \mathrm{CO}$ to ignition. A correlation coefficient of -0.2 was calculated between the percent FFA of the oil and the time between the low $\mathrm{CO}$ measurement and ignition. This implies a weak to negligible negative relationship may exist. 


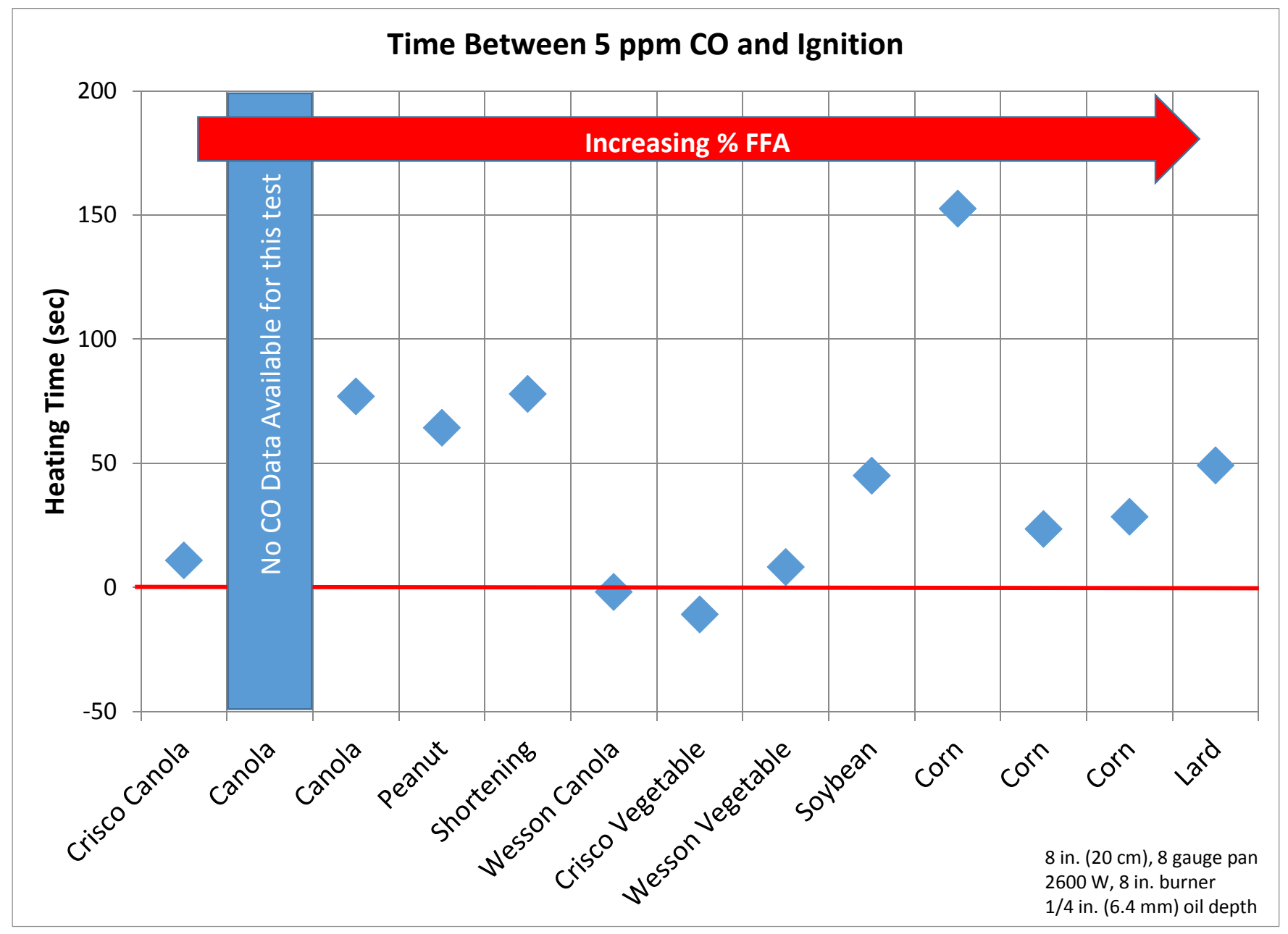

Figure 12 - Available time between 5 ppm CO measurement and ignition for various oils.

The average pan temperatures measured during the 90 seconds leading up until ignition and at the time $1.5 \% / \mathrm{ft}(5 \% / \mathrm{m})$ smoke was measured for the various oil types are shown in Figure 13 . The averaged values reported include all spatial locations as well as data 3 seconds prior to and 3 seconds after each noted time. The average pan temperatures are shown together with the percent FFA of the oils tested. 


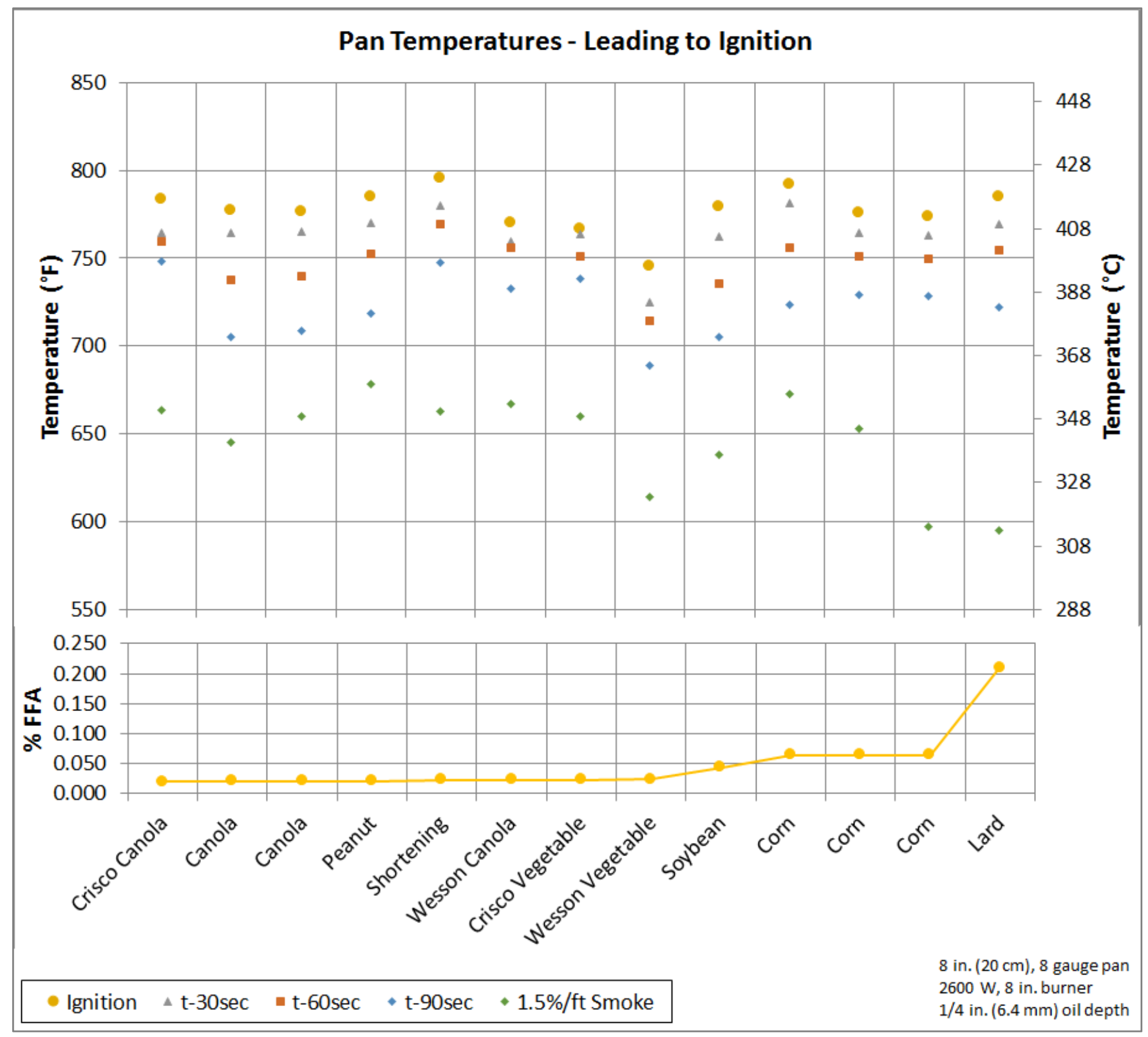

Figure 13 - Average pan temperatures approaching ignition for various oils shown with oil percent FFA.

The average pan temperature at the time of ignition was $777^{\circ} \mathrm{F}\left(414^{\circ} \mathrm{C}\right)$. The lowest temperature at ignition was observed for the Wesson soybean (vegetable) oil, with an average pan temperature of $745^{\circ} \mathrm{F}\left(396^{\circ} \mathrm{C}\right)$. This oil also had the lowest temperatures during the time leading up to ignition. This test also showed the largest temperature change in the final 30 seconds before ignition, with the pan temperature increasing by $20^{\circ} \mathrm{F}\left(11^{\circ} \mathrm{C}\right)$. The Crisco soybean (vegetable) oil showed the smallest increase in pan temperature during the final 30 seconds, increasing by only $3^{\circ} \mathrm{F}\left(1.7^{\circ} \mathrm{C}\right)$. Repeat corn oil tests showed a range from $774^{\circ} \mathrm{F}$ to $792^{\circ} \mathrm{F}\left(412^{\circ} \mathrm{C}\right.$ to $\left.422^{\circ} \mathrm{C}\right)$ in the average pan temperature at ignition. Repeat canola oil tests showed a range from $776^{\circ} \mathrm{F}$ to $777^{\circ} \mathrm{F}\left(413^{\circ} \mathrm{C}\right.$ to $\left.414^{\circ} \mathrm{C}\right)$ in the average pan temperature at ignition. 
The average oil temperatures measured during the 90 seconds leading up until ignition and at the time $1.5 \% / \mathrm{ft}(5 \% / \mathrm{m})$ smoke was measured for the various oil types are shown in Figure 14 . The averaged values reported include all spatial locations as well as data 3 seconds prior to and 3 seconds after each noted time. In general, tests showed that the varied oils were above $550^{\circ} \mathrm{F}\left(288^{\circ} \mathrm{C}\right)$ from 90 seconds before ignition to the ignition temperature, which was less than $750^{\circ} \mathrm{F}\left(399^{\circ} \mathrm{C}\right)$.

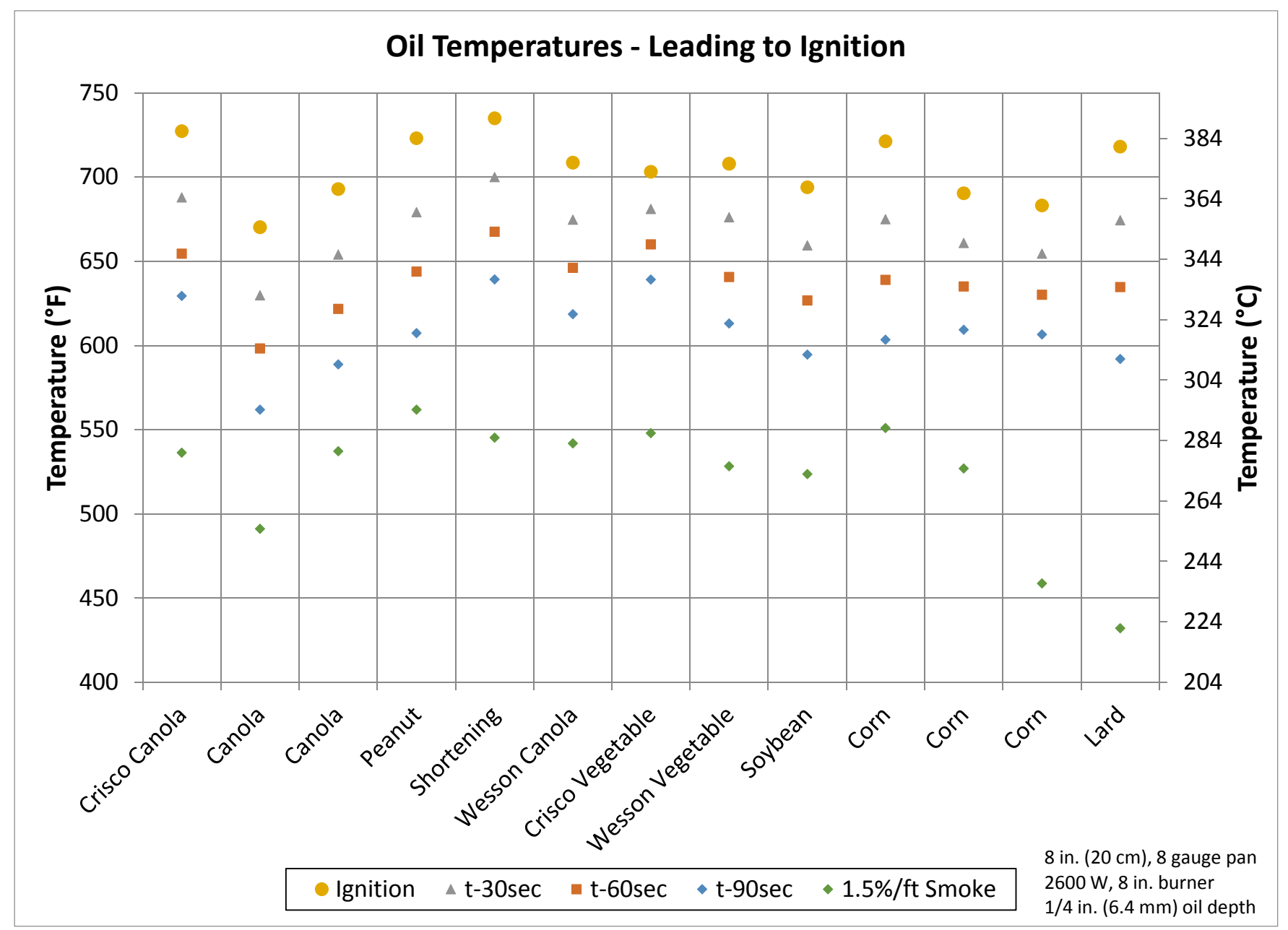

Figure 14 - Average oil temperatures approaching ignition for various oils.

The average oil temperature at ignition was $706^{\circ} \mathrm{F}\left(374^{\circ} \mathrm{C}\right)$. A negligible negative relationship was observed between the percent FFA and oil temperature at ignition. A strong negative relationship was observed between the oil FFA and the oil temperature at the time of $1.5 \% / \mathrm{ft}(5 \% / \mathrm{m})$ smoke measurement. The lowest temperature at ignition was observed for one canola oil test, with an average oil temperature of $670^{\circ} \mathrm{F}\left(354^{\circ} \mathrm{C}\right)$. This oil test also produced the lowest temperatures during the time leading up to ignition. The largest temperature change in the final 30 seconds before ignition was observed in one corn oil test, with the oil temperature increasing by $46^{\circ} \mathrm{F}\left(26^{\circ} \mathrm{C}\right)$. A larger change over a shorter period of time indicates a more rapid transition and therefore, a greater challenge to a fire prevention device. The Crisco soybean (vegetable) oil showed the smallest increase in oil temperature during the final 30 seconds, increasing by $22^{\circ} \mathrm{F}\left(12^{\circ} \mathrm{C}\right)$. Repeat corn oil tests showed a range from $683^{\circ} \mathrm{F}$ to $721^{\circ} \mathrm{F}\left(362^{\circ} \mathrm{C}\right.$ to $\left.383^{\circ} \mathrm{C}\right)$ in the average oil temperature at ignition. Repeat canola oil tests showed a range from $670^{\circ} \mathrm{F}$ to $693^{\circ} \mathrm{F}\left(355^{\circ} \mathrm{C}\right.$ to $\left.367^{\circ} \mathrm{C}\right)$ in the average oil temperature at ignition.

The average oil temperatures at the time when 1.5\%/ft $(5 \% / \mathrm{m})$ smoke was measured varied between $432^{\circ} \mathrm{F}\left(222^{\circ} \mathrm{C}\right)$ for the pork lard to $562^{\circ} \mathrm{F}\left(295^{\circ} \mathrm{C}\right)$ for the peanut oil. This result agrees well with the 
predictions of the FFA content, with pork lard having the highest FFA of $0.21 \%$ and peanut oil having among the lowest of the tested oils at $0.021 \%$. A strong negative correlation between the percent FFA and the oil temperature at the low smoke measurement was observed.

The smoke obscuration measured during the 90 seconds leading up until ignition for the various oil types are shown in Figure 15. A strong positive correlation was observed between the percent FFA and the total smoke obscuration measured 60 seconds before ignition. This agrees with the observation that smoke was produced at lower pan and oil temperatures for oils with greater percent FFA. Lower smoke production temperature, implies greater total smoke close to ignition. It should be noted that the smoke measurement lasers were viewed over a path length of $4 \mathrm{ft}(1.22 \mathrm{~m})$. Therefore, smoke obscurations greater than $25 \% / f t(82 \% / m)$ could not be measured, as they would result in a total signal reduction of $100 \%$. At the time of ignition, nearly all tested oils displayed a maximum measureable level of smoke. However, this saturation of the measurement only occurred in the final 30 seconds of testing before ignition, however, and therefore the measurements leading up to ignition do provide meaningful data.

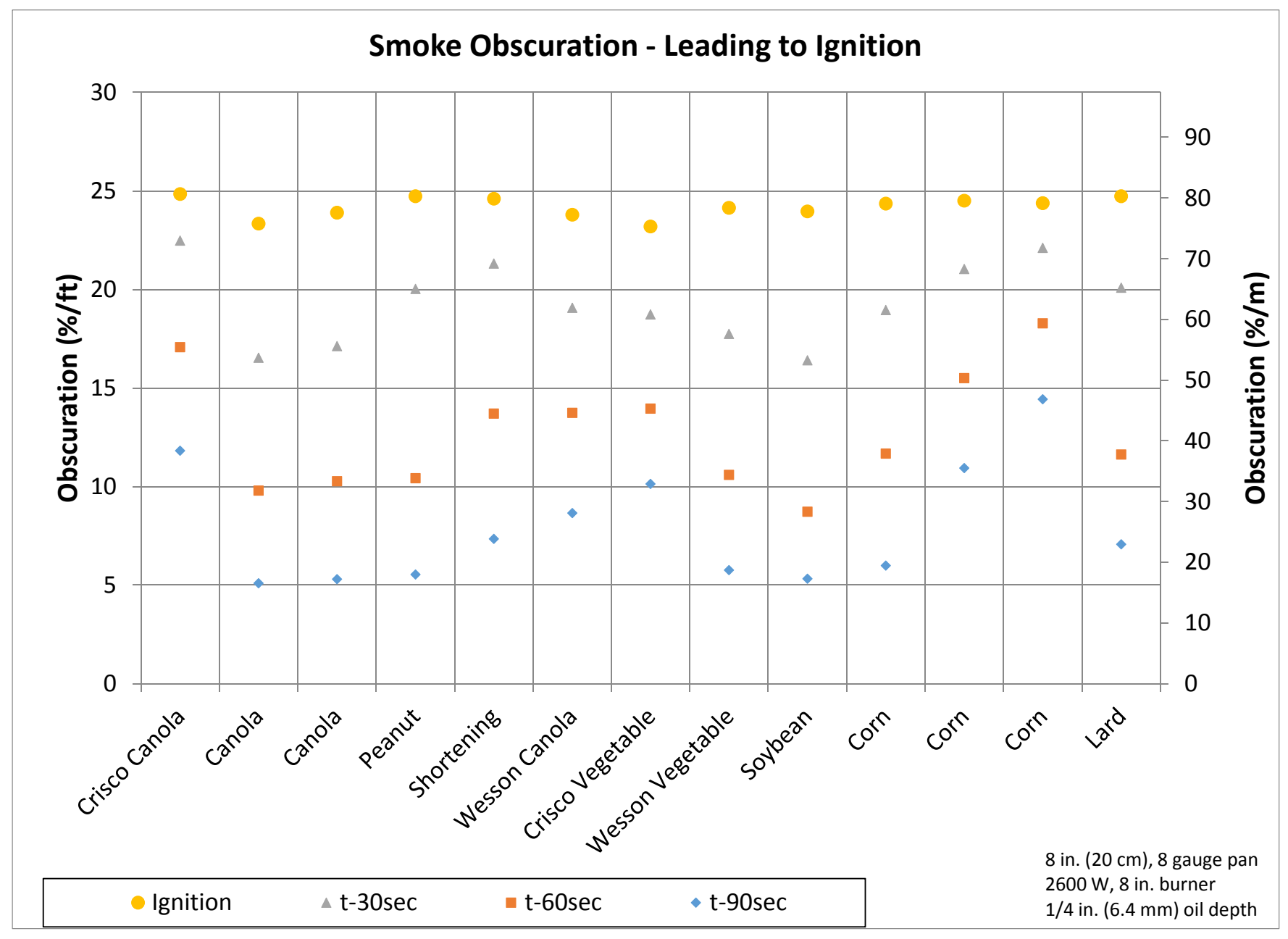

Figure 15 - Average smoke obscuration approaching ignition for various oils

Similar to the oil temperature trends, the lower the smoke measurements prior to ignition, the more challenging the test source to technologies that rely on visible or smoke signatures. The lowest smoke concentration 30 seconds before ignition was observed for the industrial soybean oil, reporting an average obscuration of $16 \% / \mathrm{ft}(52 \% / \mathrm{m})$. This oil also reported the lowest smoke concentrations during the time leading up to ignition. Repeat corn oil tests showed a range from 19 to 22\%/ft (62 to 
$73 \% / \mathrm{m})$ in the average smoke obscuration 30 seconds before ignition. Repeat canola oil tests both reported 17\%/ft $(56 \% / \mathrm{m})$ average smoke obscuration 20 seconds before ignition.

\subsection{Aged/Used Oil}

Fire tests were conducted by artificially "aging" the commercial oils by continuous heating at $400^{\circ} \mathrm{F}$ $\left(204^{\circ} \mathrm{C}\right)$ for 8 hours. In addition, a sample of used soybean (vegetable) oil was obtained from a fast food restaurant deep fryer in order to evaluate a used oil. All aged/used oil evaluation tests were conducted on the $8 \mathrm{in}$. $(20 \mathrm{~cm})$ burner of the 2600 W GE range, in an $8 \mathrm{in}$. $(20 \mathrm{~cm})$ diameter, 8 gauge aluminum frying pan. A total of $13.4 \mathrm{in}^{3}(220 \mathrm{~mL})$ of oil was used for each test, resulting in an initial oil depth of $1 / 4$ in. $(6.4 \mathrm{~mm})$. The total heating times required to reach ignition are shown in Figure 16.

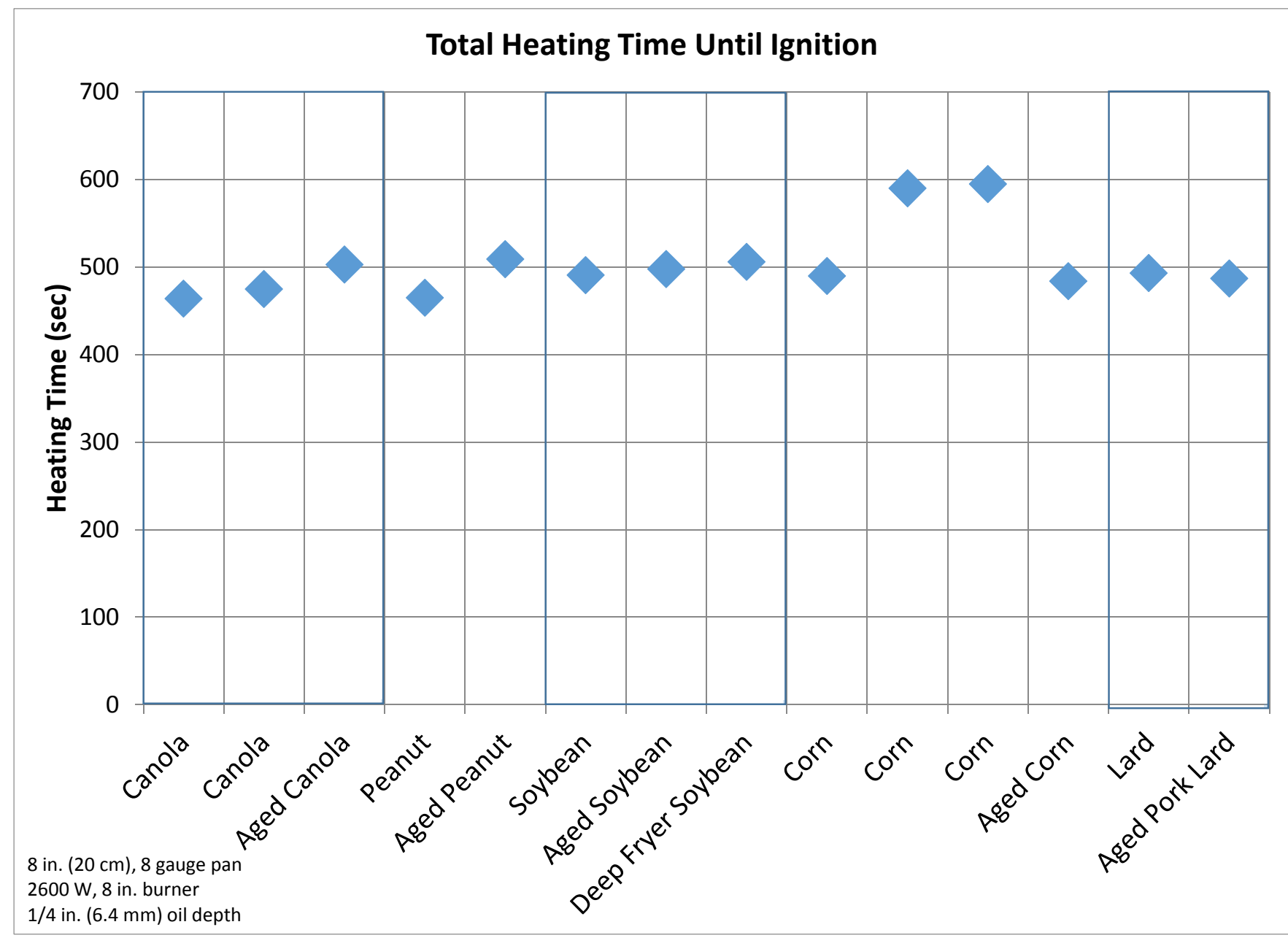

Figure 16 - Heating times until ignition for various aged/used oils.

The average time to ignition for all fresh and aged oil samples was 503 seconds (8.4 minutes). The shortest time to ignition was observed for one of two commercial grade canola oils tests, with ignition occurring after 464 seconds (7.7 minutes). The longest time to ignition occurred in fresh corn oil, with ignition occurring after 595 seconds (9.9 minutes). The time to ignition was observed to increase for soybean, canola and peanut oil due to aging, with peanut oil showing the greatest increase of 44 seconds. The ignition time of the used soybean oil was unchanged from the new soybean oil. The ignition time of the aged pork lard and corn oil were decreased due to aging.

The time that initial smoke measurements of $1.5 \% / \mathrm{ft}(5 \% / \mathrm{m})$ were made before ignition for each test are shown in Figure 17. The available time between detection of smoke and ignition was increased for 
aged/used soybean, canola, and peanut oil. The change in time varied between repeat corn oil tests and the available time was decreased through aging of pork lard.

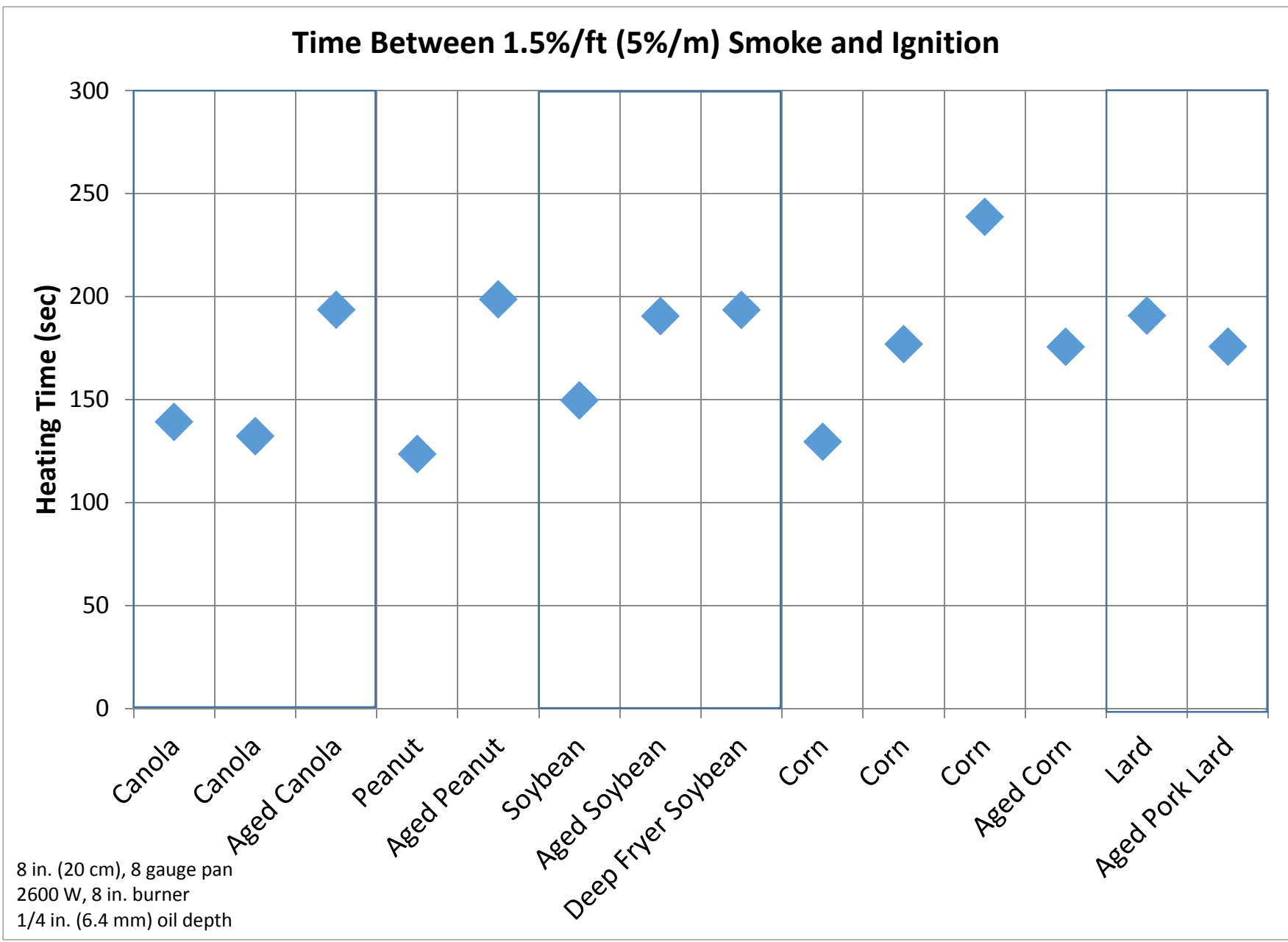

Figure 17 - Available time between 1.5\%ft (5\%/m) smoke measurement and ignition for aged/used oils.

The time that initial CO measurements of $5 \mathrm{ppm}$ were made before ignition for each test are shown in Figure 18. In nearly all cases, the available window for $\mathrm{CO}$ detection was reduced for aged/used oils. This was true for all tested oils except for two of the repeat corn oil tests.

The average pan temperatures measured during the 90 seconds leading up until ignition and at the time $1.5 \% / \mathrm{ft}(5 \% / \mathrm{m})$ smoke was measured for the aged/used oils are shown in Figure 19 . The averaged values reported include all spatial locations as well as data 3 seconds prior to and 3 seconds after each noted time.

The ignition temperature of the aged oils were observed to decrease for the soybean, corn, peanut oil, and pork lard, with soybean oil showing the greatest decrease of $20^{\circ} \mathrm{F}\left(11^{\circ} \mathrm{C}\right)$. The ignition temperature of the canola oil did not change, although lower pan temperatures were measured prior to ignition for the aged canola oil.

No consistent trend due to aging was observed for the pan temperatures at the time measureable smoke was produced. The used deep fryer oil produced smokes at a pan temperature $486^{\circ} \mathrm{F}\left(252^{\circ} \mathrm{C}\right)$, $152^{\circ} \mathrm{F}\left(84^{\circ} \mathrm{C}\right)$ lower than the fresh soybean oil. 


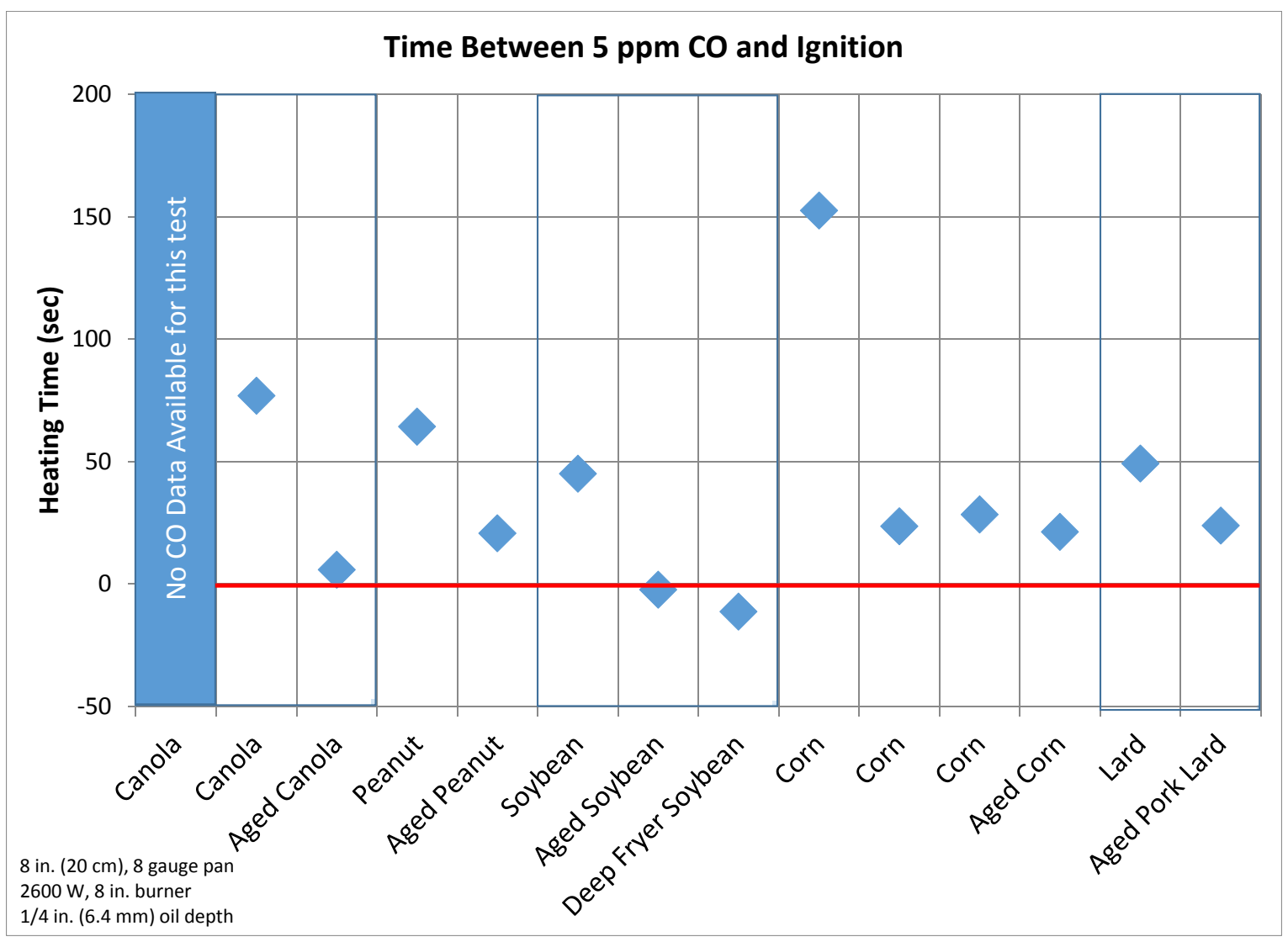

Figure 18 - Available time between 5 ppm CO measurement and ignition for aged/used oils.

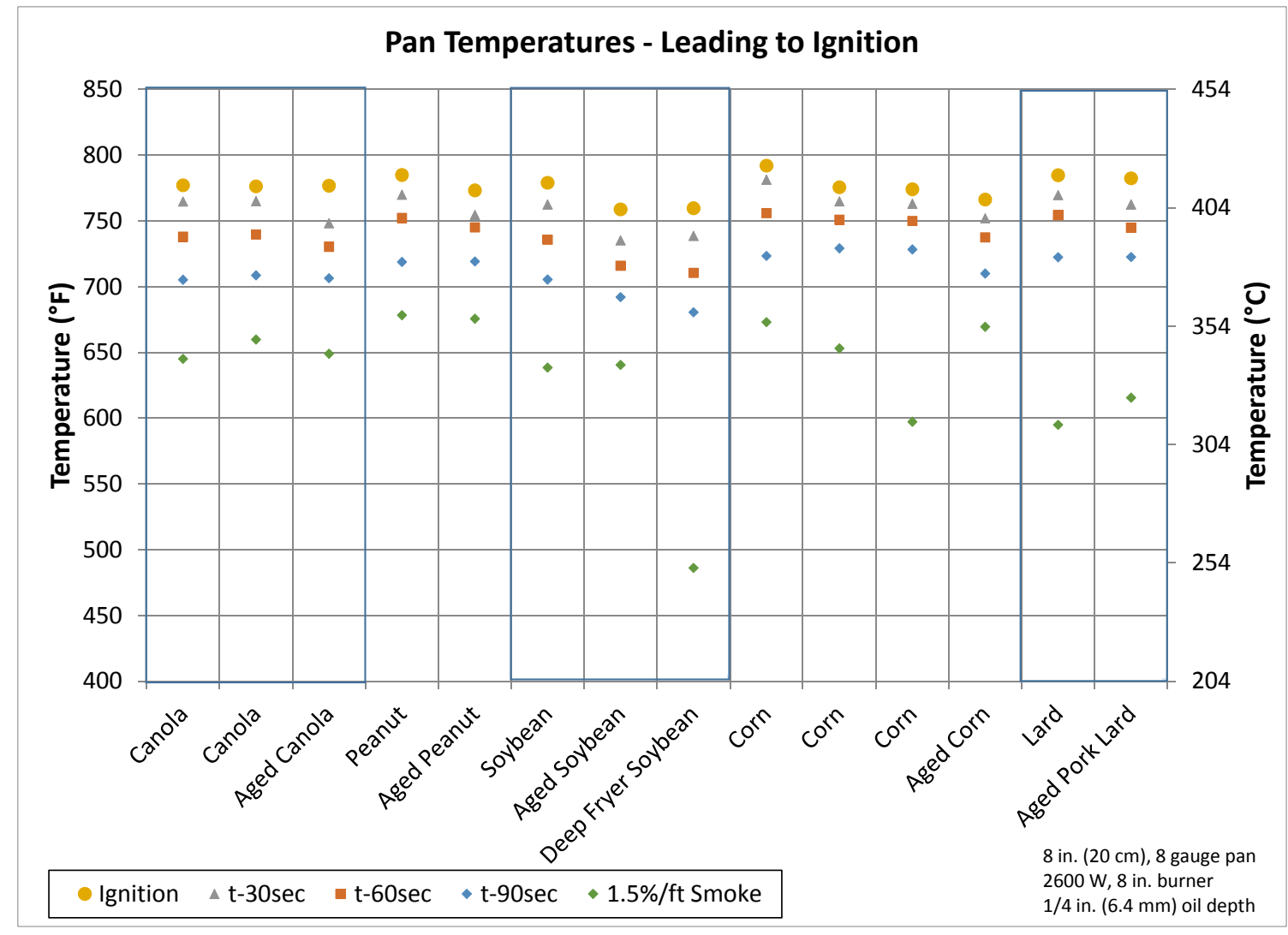

Figure 19 - Average pan temperatures approaching ignition for aged/used oils. 
The average oil temperatures measured during the 90 seconds leading up until ignition and at the time $1.5 \% / \mathrm{ft}(5 \% / \mathrm{m})$ smoke was measured for the aged/used oils are shown in Figure 20 . The averaged values reported include all spatial locations as well as data 3 seconds prior to and 3 seconds after each noted time.

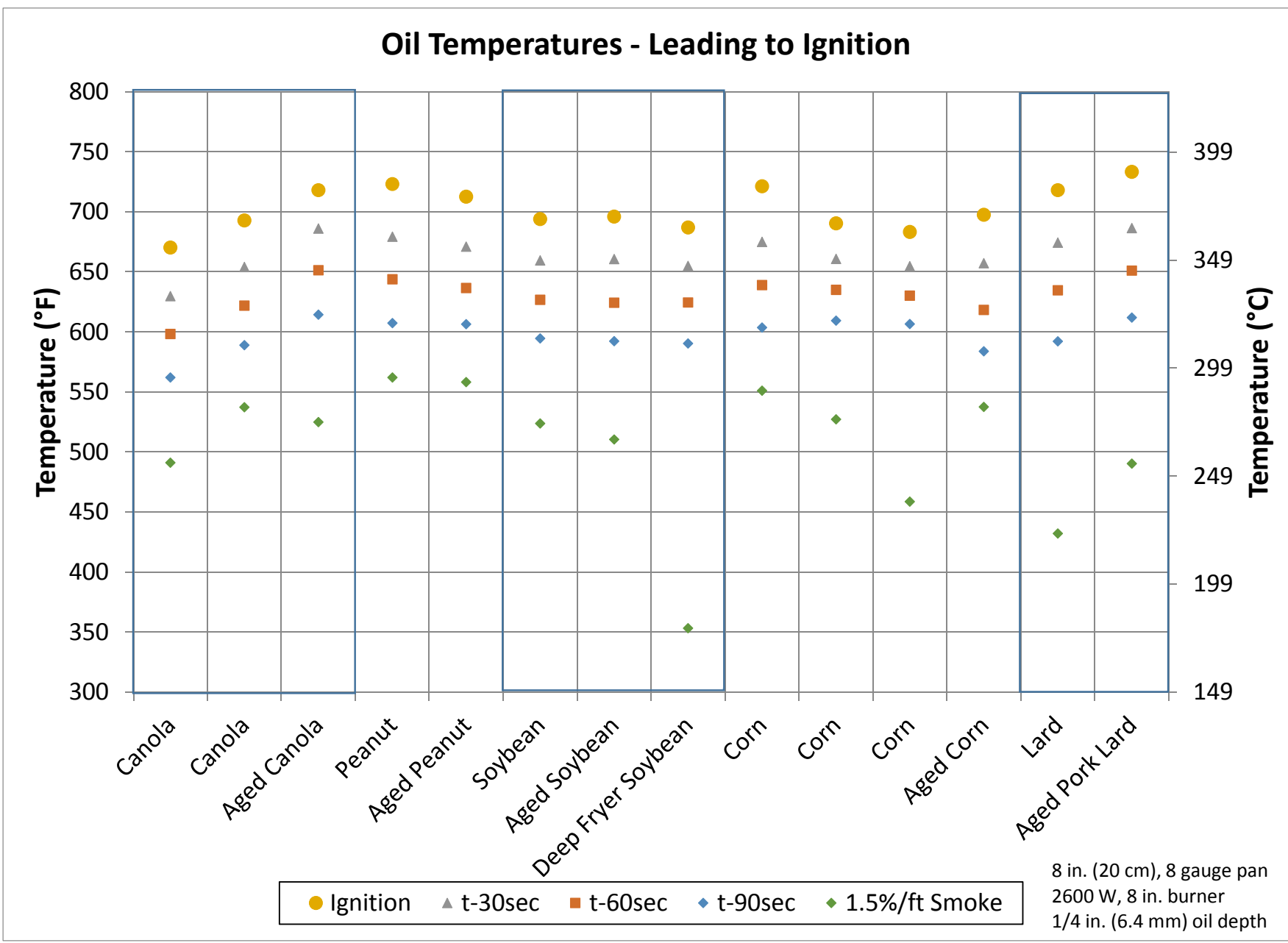

Figure 20 - Average oil temperatures approaching ignition for aged/used oils.

Unlike the pan temperatures, the oil ignition temperatures were not observed to decrease for the aged/used oils. The oil ignition temperatures in the aged pork lard, soybean, and canola oils were observed to increase compared to the fresh oil tests. However, the increases are within the general variations of repeat test data.

No consistent trend due to aging was observed for the oil temperature at the time $1.5 \% / \mathrm{ft}(5 \% / \mathrm{m})$ smoke was produced. The used deep fryer oil produced smoke at an oil temperature $353^{\circ} \mathrm{F}\left(178^{\circ} \mathrm{C}\right)$, $171^{\circ} \mathrm{F}\left(95^{\circ} \mathrm{C}\right)$ lower than the fresh soybean oil. In general, a lower smoke temperature would indicate the creation of an earlier visible signature with more time before ignition occurs.

The smoke obscuration measured during the 90 seconds leading up until ignition for the aged/used oils are shown in Figure 21. It should be noted that the smoke measurement lasers were viewed over a path length of $4 \mathrm{ft}(1.22 \mathrm{~m})$. Therefore, smoke obscurations greater than $25 \% / \mathrm{ft}(82 \% / \mathrm{m})$ could not be measured, as they would result in a total signal reduction of $100 \%$. At the time of ignition, nearly all tested oils displayed a maximum measureable level of smoke. However, this saturation of the measurement only occurred in the final 30 seconds of testing before ignition, and thus the measurements leading up to ignition do provide meaningful data. 


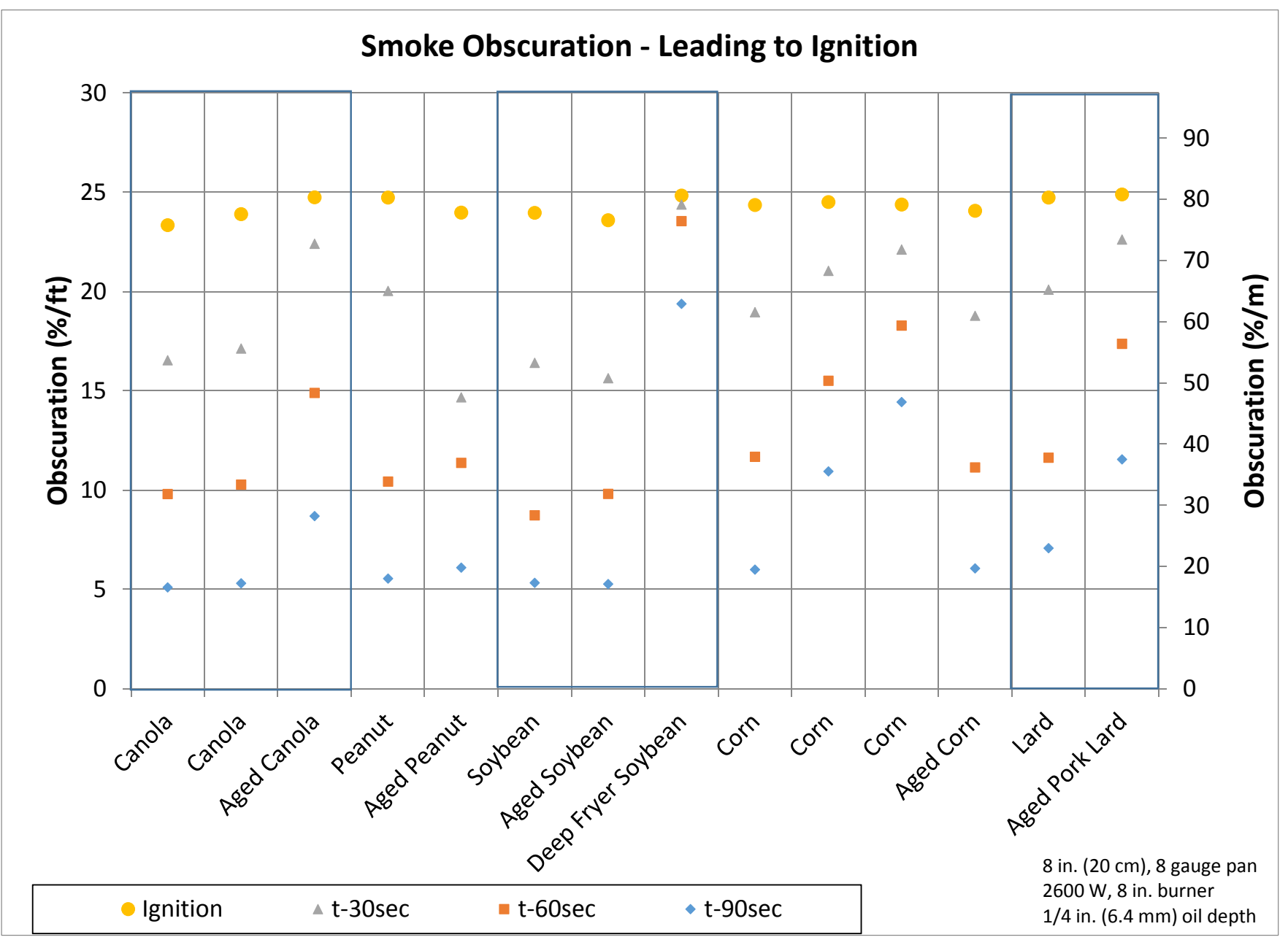

Figure 21 - Average smoke obscuration approaching ignition for aged/used oils.

The smoke concentrations before ignition for aged canola oil and pork lard were increased compared to fresh oils, while the smoke concentrations for aged peanut, soybean, and corn oil tended to decrease compared to the fresh oils. The lowest smoke concentration 30 seconds before ignition was observed for the aged peanut oil, reporting an average obscuration of $15 \% / \mathrm{ft}(49 \% / \mathrm{m})$. The smoke output of the used fryer oil 90 seconds before ignition was $14 \% / \mathrm{ft}(46 \% / \mathrm{m})$ greater than that of the fresh soybean oil. As was noted for the pan and oil temperatures, the used fryer oil produced greater quantities of smoke longer before ignition than unused oil.

\subsection{Range Power and Burner}

Fire tests were conducted on two ranges with different maximum power levels and burner coil designs. Tests were conducted at the maximum power level of one range $(2600 \mathrm{~W})$, and at the maximum power level of the other range $(2100 \mathrm{~W})$ on both range types. The higher power range was set to a burner power of $83 / 4$ (out of 10) in order to match the total power output of the burners. The burner power was matched by reducing the burner cycling time by $19 \%$, as measured by total current.

In addition, a test was run on the small 6 in. $(15 \mathrm{~cm}) 1500 \mathrm{~W}$ burner of the higher power range at its maximum power setting. All range/burner evaluation tests were conducted in an $8 \mathrm{in} .(20 \mathrm{~cm})$ diameter, 8 gauge aluminum frying pan. A total of $13.4 \mathrm{in}^{3}(220 \mathrm{~mL})$ of oil was used for each test, resulting in an initial oil depth of $1 / 4$ in. $(6.4 \mathrm{~mm})$ The total heating times required to reach ignition are shown in Figure 22. 


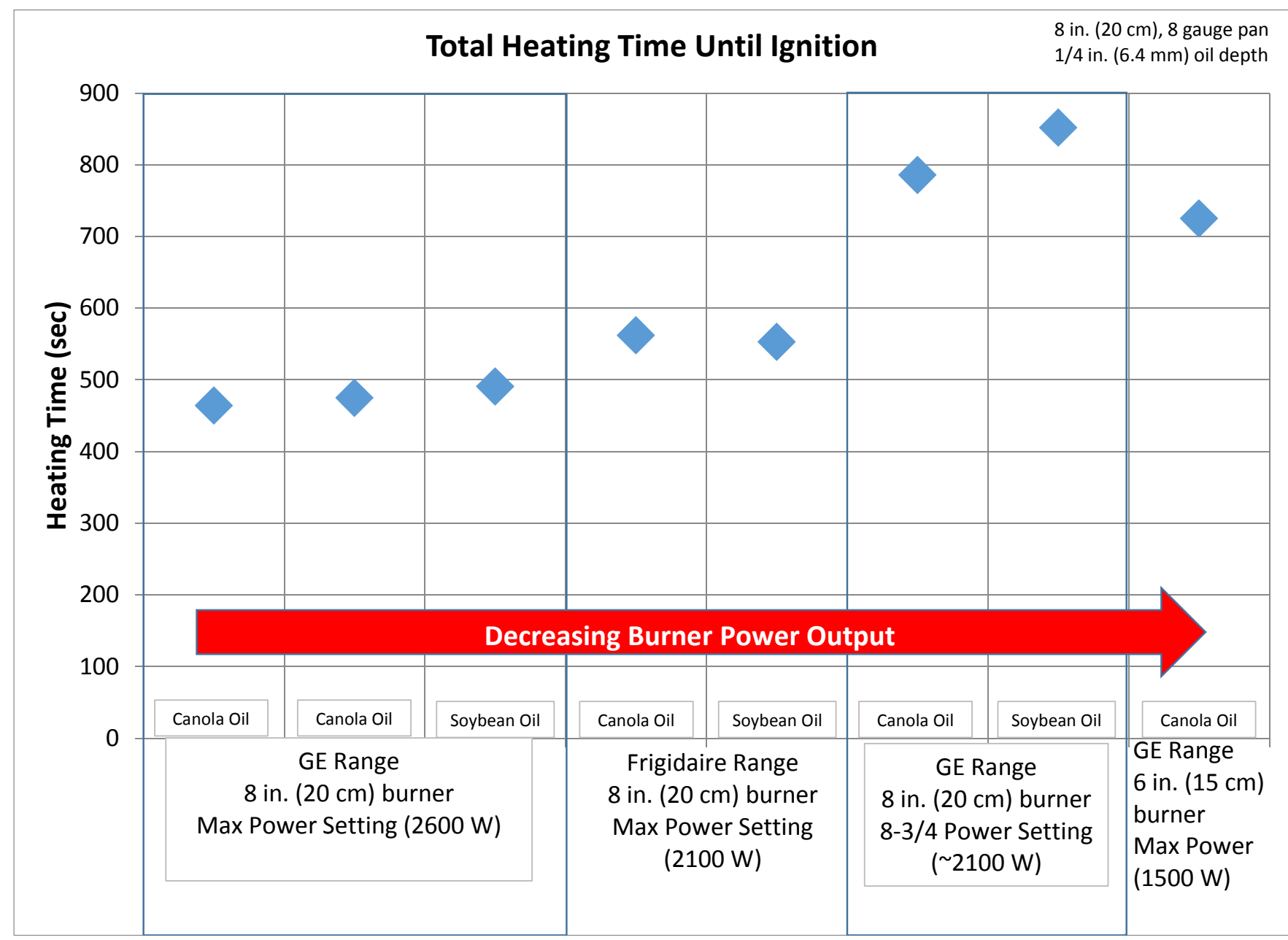

Figure 22 - Heating times until ignition for various range power levels.

The time to ignition was observed to increase with decreasing range power, indicating a strong negative correlation. The shortest time to ignition was observed for the GE range at its highest power setting for both canola and soybean oils. The $2100 \mathrm{~W}$ Frigidaire range produced ignition 62 and 95 seconds slower than the 2600 W GE for soybean and canola oil, respectively. When the power output of the GE range was reduced to $2100 \mathrm{~W}$, however, the ignition times for the oils increased by 401 seconds and 317 seconds for soybean and canola oil, respectively. Despite matching the total power output between the two ranges, the ignition time was greater for the range with a coil operating with cyclic, rather than continuous heating. This effect may be due to the heat transfer rate of the burner coil, but the GE range has more coils than the Frigidaire range and the ignition time for the $1500 \mathrm{~W}$ GE burner with continuous heating was faster than the ignition time for the large burner with cyclic heating.

The time between achieving smoke measurements of $1.5 \% / \mathrm{ft}(5 \% / \mathrm{m})$ and ignition for each test are shown in Figure 23. Such smoke measurements in the collection hood were recorded between 132 seconds (2.2 minutes) and 539 seconds (9.0 minutes) before ignition occurred. The shortest window between $1.5 \% / \mathrm{ft}(5 \% / \mathrm{m})$ smoke and ignition was observed for the $2600 \mathrm{~W}$ range tests. The longest window between smoke and ignition was observed for the reduced power $2100 \mathrm{~W}$ GE range tests.

The time CO measurements of 5 ppm were made before ignition for each test are shown in Figure 24. Such CO measurements in the collection hood were recorded between 77 seconds (1.3 minutes) before ignition and 9 seconds ( 0.2 minutes) after ignition occurred. The longest available windows for CO response were observed in the tests on the 2600 W GE burner. Reduction in the burner power generally decreased the time between the measurement of $\mathrm{CO}$ and ignition. 


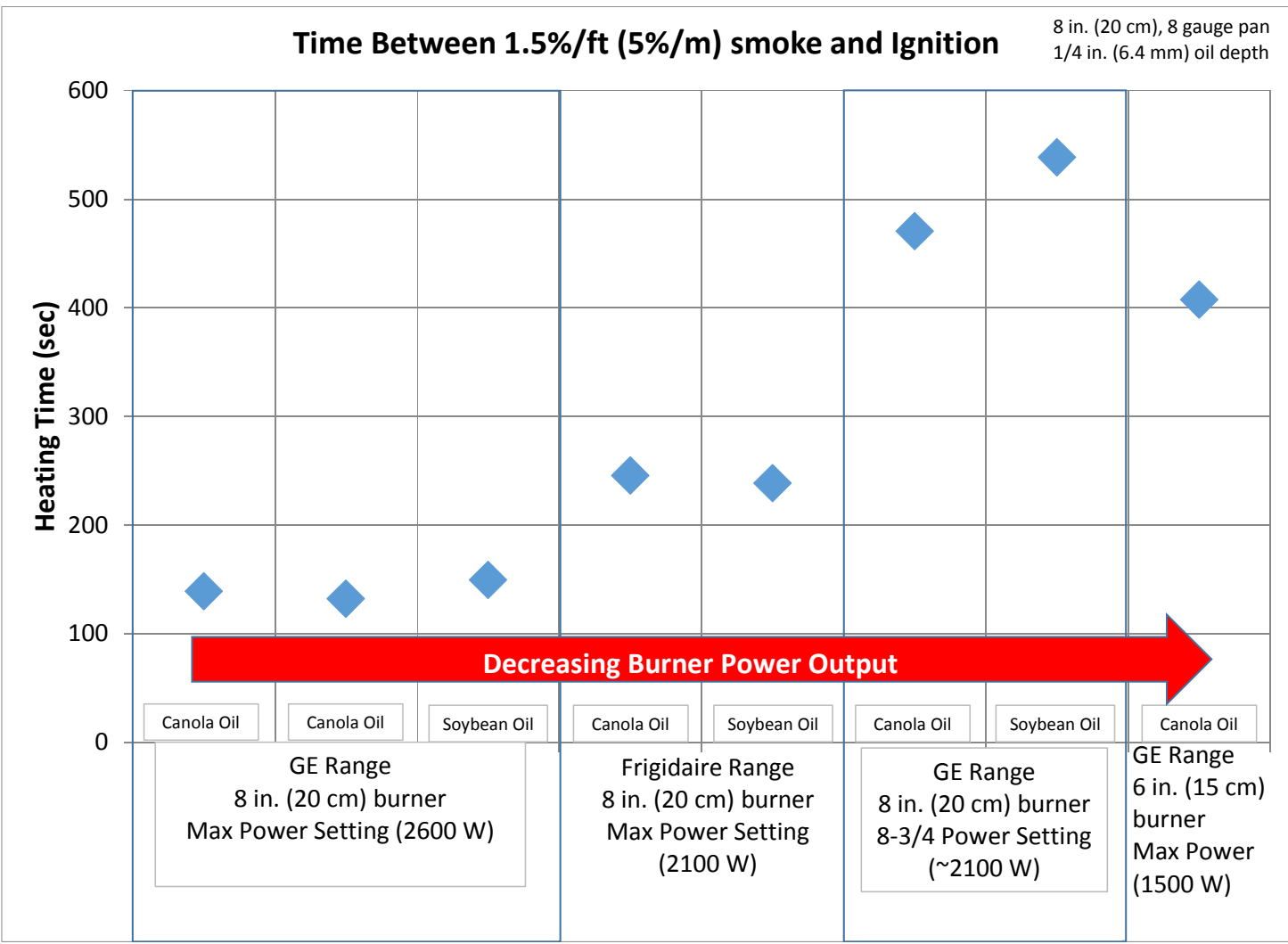

Figure 23 - Available time between 1.5\%ft (5\%/m) smoke measurement and ignition for various range power levels.

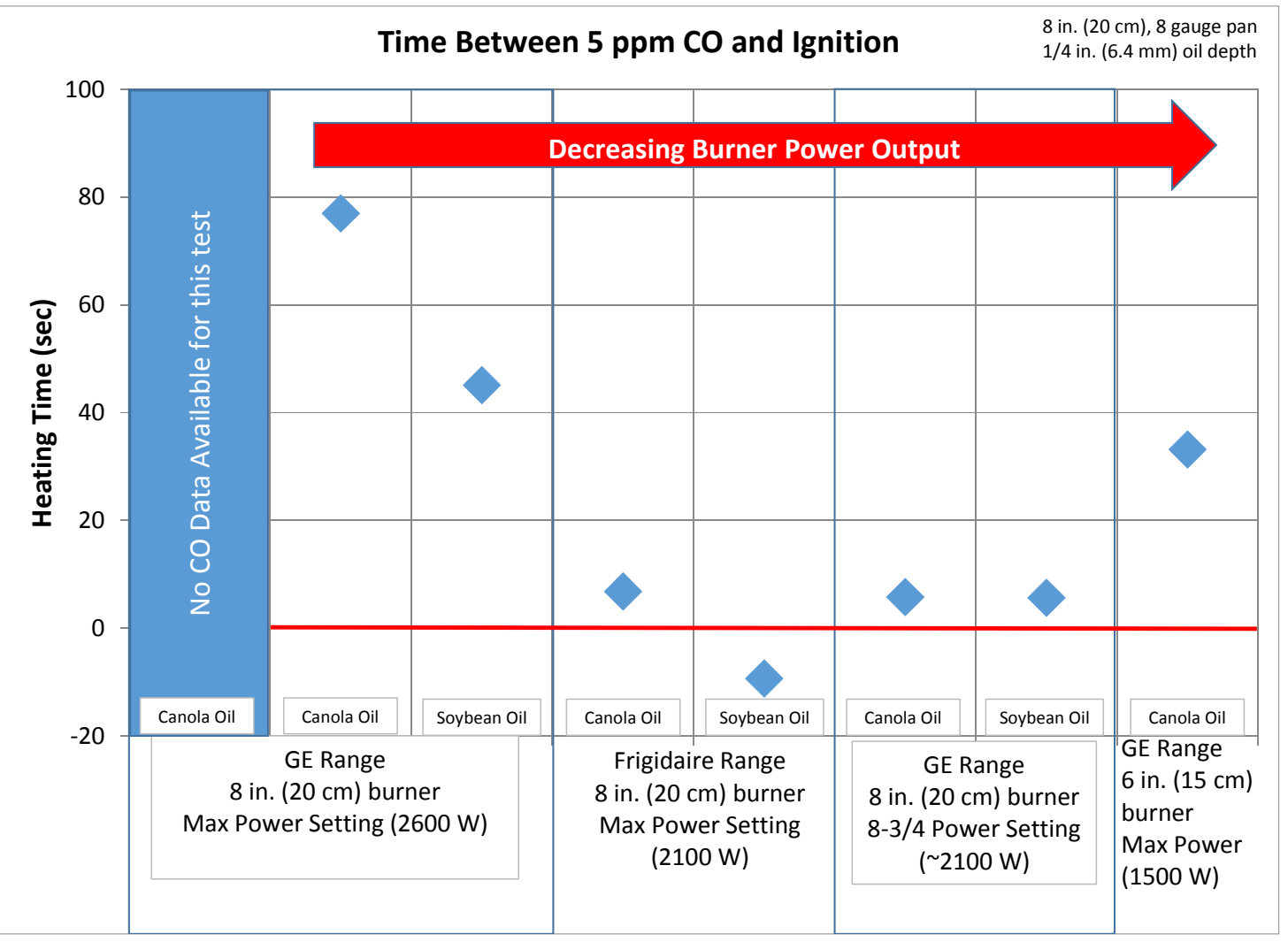

Figure 24 - Available time between 5 ppm CO measurement and ignition for various range power levels. 
The average pan temperatures measured during the 90 seconds leading up until ignition and at the time 1.5\%/ft $(5 \% / \mathrm{m})$ smoke was measured for the various ranges and burners are shown in Figure 25. The averaged values reported include all spatial locations as well as data 3 seconds prior to and 3 seconds after each noted time.

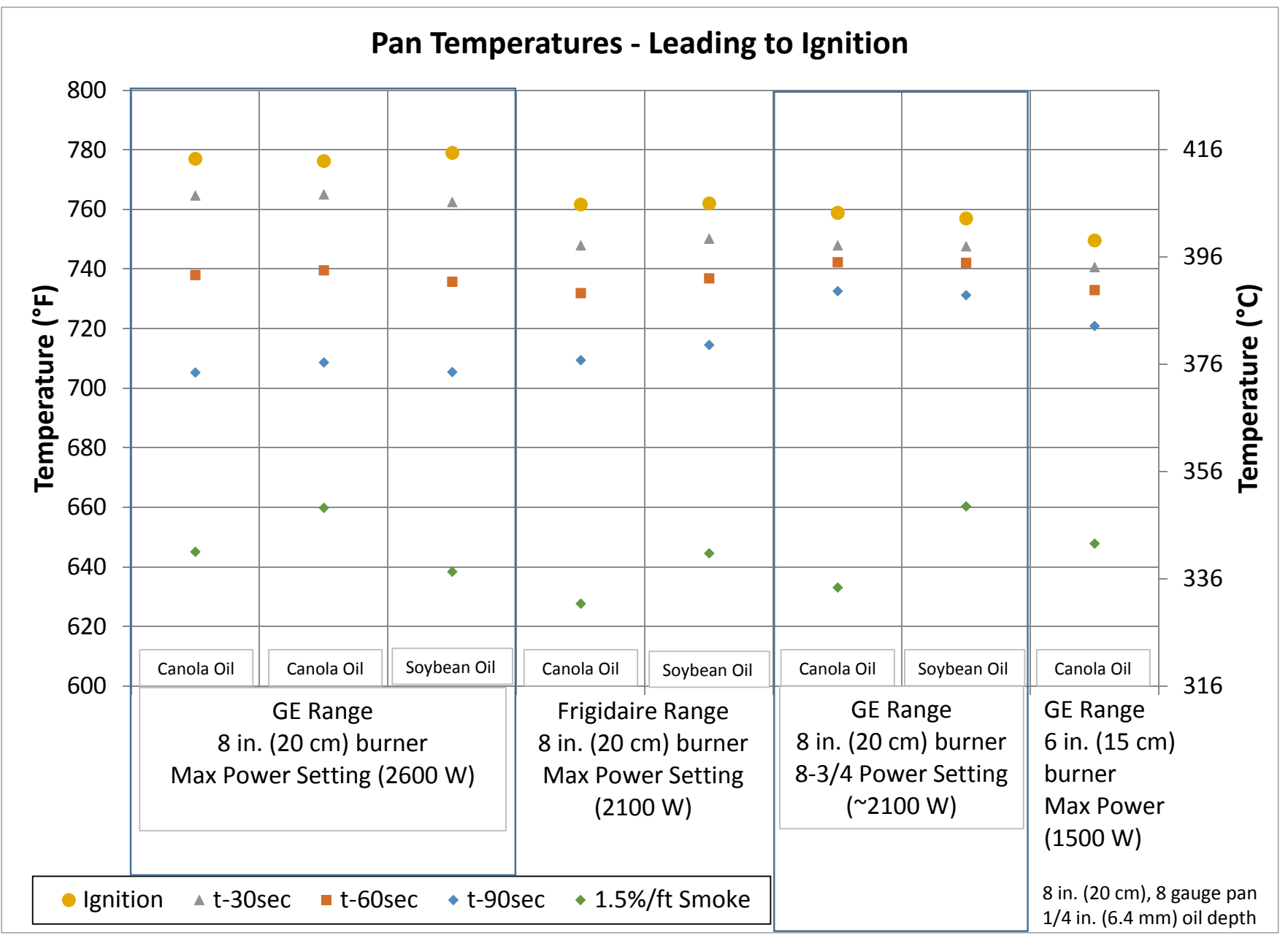

Figure 25 - Average pan temperatures approaching ignition for various range power levels.

Reducing the burner power was observed to decrease the average pan temperature at ignition. A strong positive relationship was observed between the burner power and the average pan temperature at ignition. For the range of burners and wattage conditions evaluated, the average pan temperatures at ignition and 90 seconds before were $765^{\circ} \mathrm{F}\left(407^{\circ} \mathrm{C}\right)$ and $716^{\circ} \mathrm{F}\left(380^{\circ} \mathrm{C}\right)$, respectively. The lowest temperature at ignition was observed for the canola oil on the small $6 \mathrm{in}$. $(15 \mathrm{~cm}), 1500 \mathrm{~W}$ GE burner, reporting an average pan temperature of $750^{\circ} \mathrm{F}\left(399^{\circ} \mathrm{C}\right)$. The lowest temperatures measured 60 and 90 seconds before ignition were observed for the $2600 \mathrm{~W}$ tests with the fastest heating rate. It is important to recognize that the pan temperatures are typically greater than the oil temperature and at a minimum would be equal to the oil temperature.

The average oil temperatures measured during the 90 seconds leading up until ignition and at the time $1.5 \% / \mathrm{ft}(5 \% / \mathrm{m})$ smoke was measured for the various ranges and burners are shown in Figure 26 . The averaged values reported include all spatial locations as well as data 3 seconds prior to and 3 seconds after each noted time. 


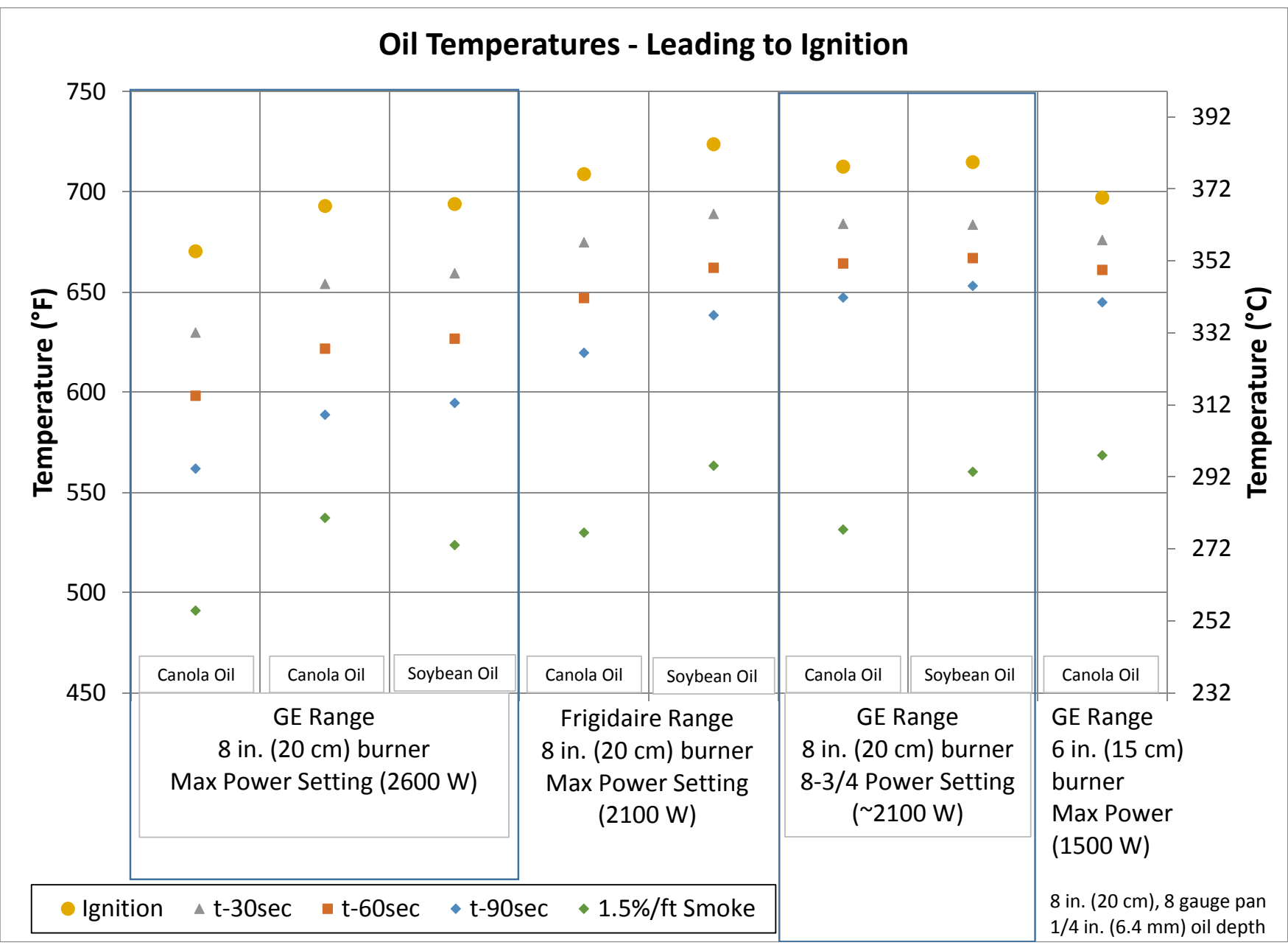

Figure 26 - Average oil temperatures approaching ignition for various range power levels.

A strong negative relationship was observed between the range power and the average oil temperatures at ignition. This implies that the oil temperatures were greater for lower range power. This is the opposite relationship observed for the average pan temperatures, which were reduced by reducing range power. The lower heating rates of the low power burners also increased the average oil temperatures in the time approaching ignitions.

The lowest temperature at ignition was observed for one canola oil test, reporting an average oil temperature of $670^{\circ} \mathrm{F}\left(354^{\circ} \mathrm{C}\right)$. This oil also reported the lowest temperatures during the time leading up to ignition. The lowest temperatures measured 60 and 90 seconds before ignition were observed for the $2600 \mathrm{~W}$ tests with the fastest heating rate.

The smoke obscuration measured during the 90 seconds leading up until ignition for the various ranges and burners are shown in Figure 27. It should be noted that the smoke measurement lasers were viewed over a path length of $4 \mathrm{ft}(1.22 \mathrm{~m})$. Therefore, smoke obscurations greater than $25 \% / \mathrm{ft}(82$ $\% / \mathrm{m}$ ) could not be measured, as they would result in a total signal reduction of $100 \%$. At the time of ignition, nearly all tested oils displayed a maximum measureable level of smoke. However, this saturation of the measurement only occurred in the final 30 seconds of testing before ignition, and thus the measurements leading up to ignition do provide meaningful data. 


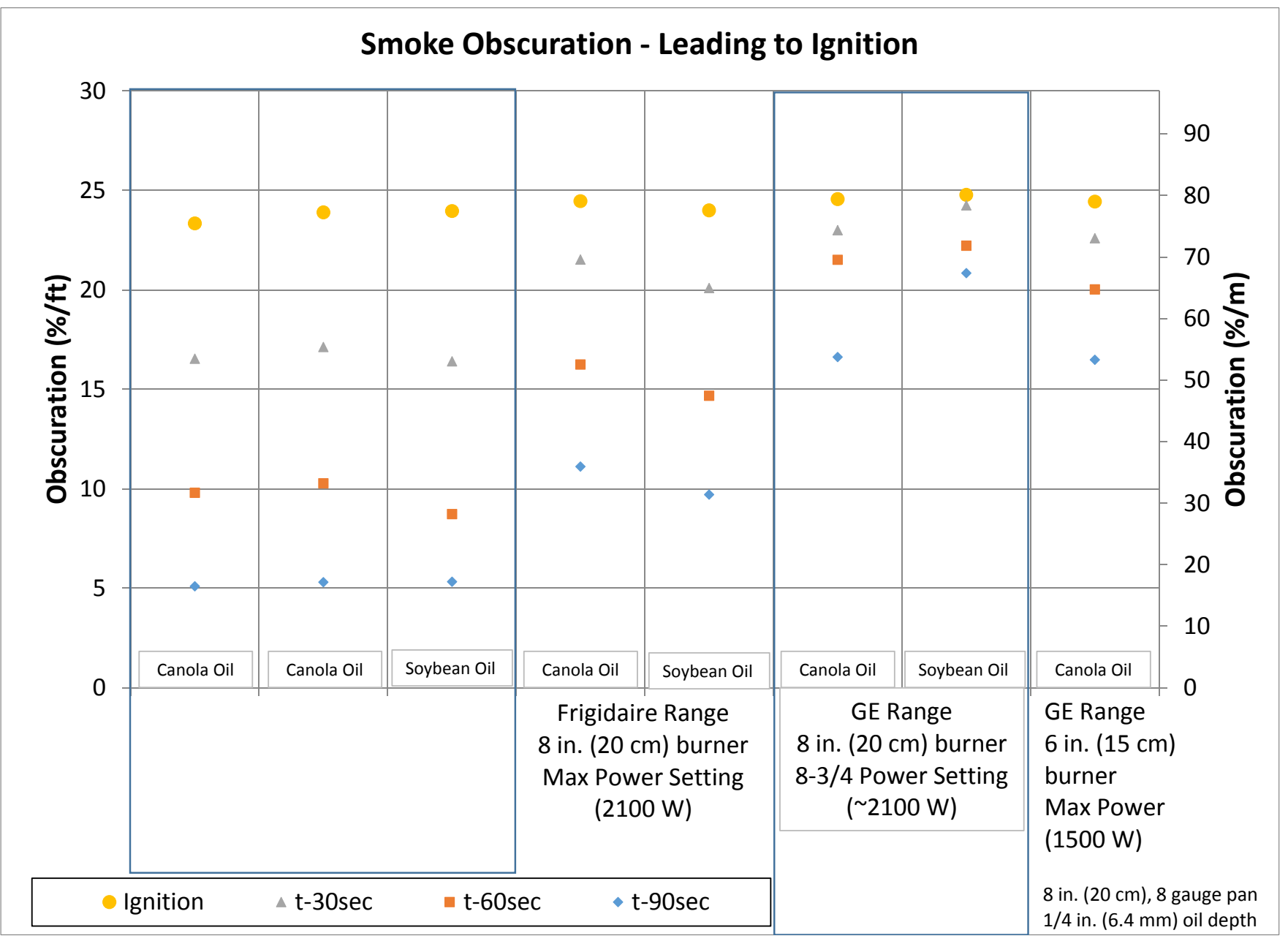

Figure 27 - Average smoke obscuration approaching ignition for various range power levels.

The smoke concentrations leading up to ignition were increased by reducing the overall range power. A strong negative correlation between the range power and pre-ignition smoke concentration was observed. The lowest smoke concentrations measured before ignition were observed for the $2600 \mathrm{~W}$ burner tests. The smoke concentrations measured prior to ignition were the greatest for the reduced power 2100 W GE burner tests.

\subsection{Pan Thickness and Diameter}

Fire tests were conducted using pans of varying thicknesses and diameters. Aluminum pans of 8 in. $(20 \mathrm{~cm})$ diameter with 5 gauge $(0.1819 \mathrm{in} .(4.6 \mathrm{~mm}))$ and 10 gauge $(0.1019 \mathrm{in}$. $(2.6 \mathrm{~mm}))$ thicknesses were evaluated with two different oil types. In addition, 8 gauge pans $(0.1285 \mathrm{in}$. $(3.3 \mathrm{~mm})$ thick) were tested at pan diameters of 7 and $14 \mathrm{in}$. $(18$ and $36 \mathrm{~cm})$ using two different oil types. This data has been combined with the previous tests reported for $8 \mathrm{in} .(20 \mathrm{~cm}), 8$ gauge pans for each of the oils. The total heating times required to reach ignition are shown in Figure 28. 


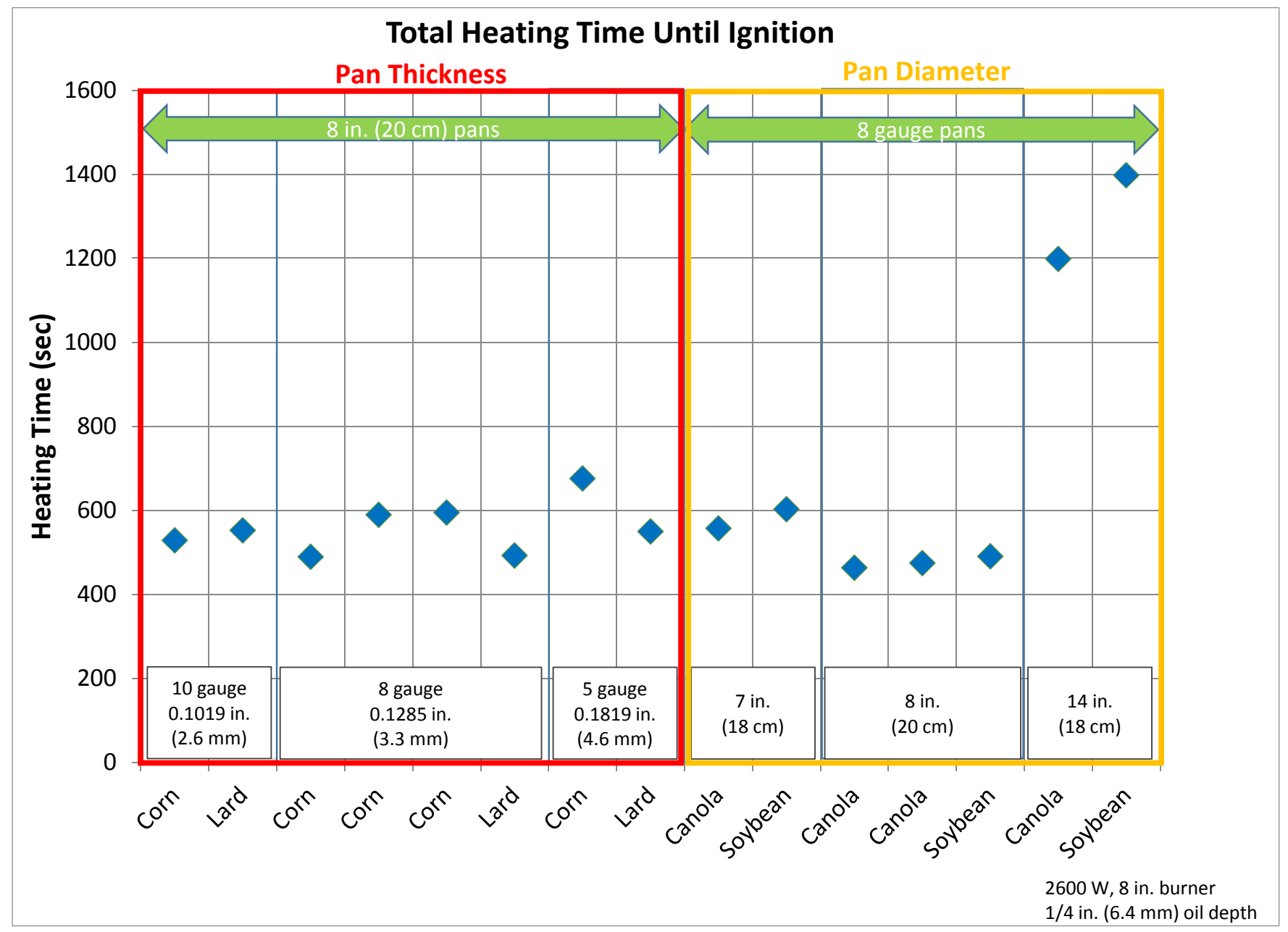

Figure 28 - Heating times until ignition for various pan thickness and diameters.

For the same size pan (8 in. $(20 \mathrm{~cm}))$, the time to ignition was observed to decrease for the corn oil in the 10 gauge pan by 147 seconds compared to the 5 gauge pan. The heating time for lard showed no distinct trend between the 10, 8 and 5 gauge pans, both decreasing and increased depending on which gauges are compared. Including data for both oils in the calculation, however, a strong positive correlation was observed between the pan thickness and the heating time until ignition.

For the same gauge pans, (8 gauge), the time to ignition was increased when using the largest pans. The volume of oil used for the $7 \mathrm{in}$. $\left(18 \mathrm{~cm}\right.$ ) pan was increased from $11.0 \mathrm{in}^{3}$ to $29.0 \mathrm{in}^{3}$ (180 $\mathrm{mL}$ to 475 $\mathrm{mL})$ for the $14 \mathrm{in}$. $(36 \mathrm{~cm})$ pans. The increase in pan diameter and oil volume increased the heating time to ignition by 795 seconds (13.3 minutes) and 641 seconds (10.7 minutes) for the soybean and canola oils, respectively.

The time that initial smoke measurements of $1.5 \% / \mathrm{ft}(5 \% / \mathrm{m})$ were made before ignition for each test are shown in Figure 29. The time between 1.5\%/ft (5\%/m) smoke and ignition was observed to decrease for the both the corn oil and lard in thinner pans. The time between measureable smoke and ignition decreased by 64 seconds for the 10 gauge corn oil compared to the 5 gauge pan. The time between measureable smoke and ignition decreased by 41 seconds for the pork lard in the thinner pan. A strong positive correlation between the pan thickness and the time between the low smoke measurement and ignition was calculated. 


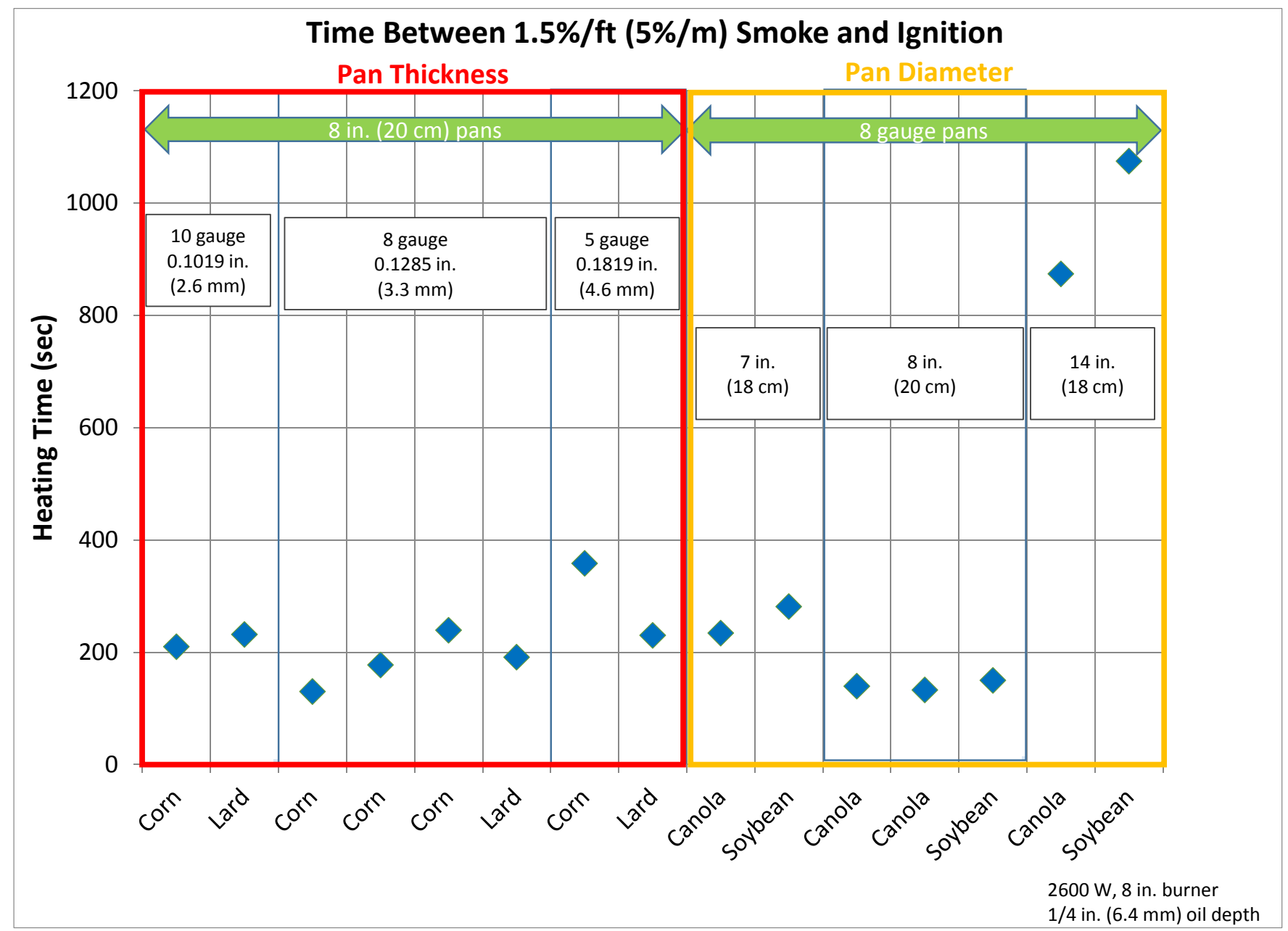

Figure 29 - Available time between $1.5 \% \mathrm{ft}(5 \% / \mathrm{m})$ smoke measurement and ignition for various pan thicknesses and diameters.

The time between measurement of low smoke and ignition was also decreased by using less oil in smaller pans. The volume of oil used for the $7 \mathrm{in}$. $(18 \mathrm{~cm})$ pan was increased from $11.0 \mathrm{in}^{3}$ to $29.0 \mathrm{in}^{3}$ $(180 \mathrm{~mL}$ to $475 \mathrm{~mL})$ for the $14 \mathrm{in.}(36 \mathrm{~cm})$ pans. The increase in pan diameter and oil volume increased the time between measurement of smoke and ignition by 624 seconds (10.4 minutes) and 404 seconds (6.7 minutes) for the soybean and canola oils, respectively. A very strong positive correlation between the pan diameter and the time between the low smoke measurement and ignition was calculated.

The time that initial CO measurements of $5 \mathrm{ppm}$ were made before ignition for each test are shown in Figure 30. Initial measurements of $\mathrm{CO}$ in the collection hood were recorded between 21 seconds and 73 seconds for the pan thickness tests. The time was increased with thinner pans for both corn oil and pork lard, but the time increased by only 1 second and 4 seconds, respectively.

The time between the $5 \mathrm{ppm}$ CO measurement and ignition did not change consistently with pan size. The 7 in. $(18 \mathrm{~cm})$ soybean, 7 in. $(18 \mathrm{~cm})$ canola, and 14 in. $(36 \mathrm{~cm})$ canola tests all measured $5 \mathrm{ppm}$ $\mathrm{CO}$ after ignition had occurred. The $14 \mathrm{in} .(36 \mathrm{~cm})$ soybean test measured 5 ppm CO 96 seconds prior to ignition, however. No trend can be determined from this data. 


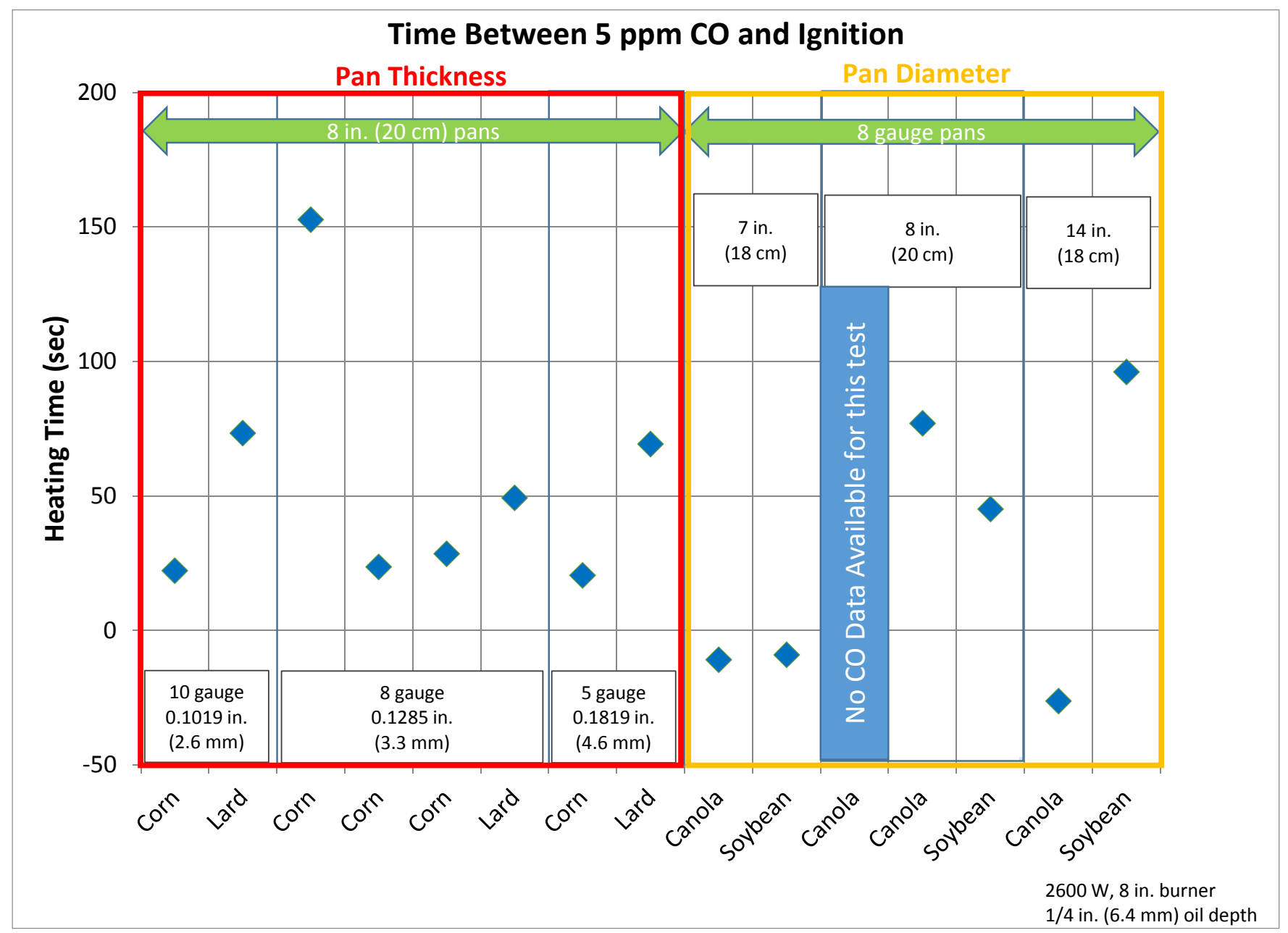

Figure 30 - Available time between 5 ppm CO measurement and ignition for various pan thickness and diameters.

The average pan temperatures measured during the 90 seconds leading up until ignition and at the time of $1.5 \% / \mathrm{ft}(5 \% / \mathrm{m})$ measured smoke for various pan thicknesses and sizes are shown in Figure 31. The averaged values reported include all spatial locations as well as data 3 seconds prior to and 3 seconds after each noted time.

A weak correlation was calculated between the pan thickness and the average pan temperature at ignition. Stronger trends were observed for the pan temperatures when $1.5 \% / \mathrm{ft}(5 \% / \mathrm{m})$ smoke was produced and at 60 and 90 seconds prior to ignition. For both oils tested, the pan temperatures were greater in the thinner pan prior to ignition.

The pan temperatures measured at ignition, leading up to ignition, and at the time of smoke production were observed to reduce for larger pans containing more oil. The average pan temperature at ignition decreased from $778^{\circ} \mathrm{F}\left(414^{\circ} \mathrm{C}\right)$ to $719^{\circ} \mathrm{F}\left(382^{\circ} \mathrm{C}\right)$ for soybean oil in the 7 in. $(18 \mathrm{~cm})$ and 14 in. $(36 \mathrm{~cm})$ pans, respectively. The average pan temperature at ignition decreased from $785^{\circ} \mathrm{F}\left(418^{\circ} \mathrm{C}\right)$ to $710^{\circ} \mathrm{F}$ $\left(377^{\circ} \mathrm{C}\right)$ for canola oil in the $7 \mathrm{in} .(18 \mathrm{~cm})$ and $14 \mathrm{in} .(36 \mathrm{~cm})$ pans, respectively. Comparable reduced temperatures were observed leading up to ignition and at the time smoke was measured in the hood. 


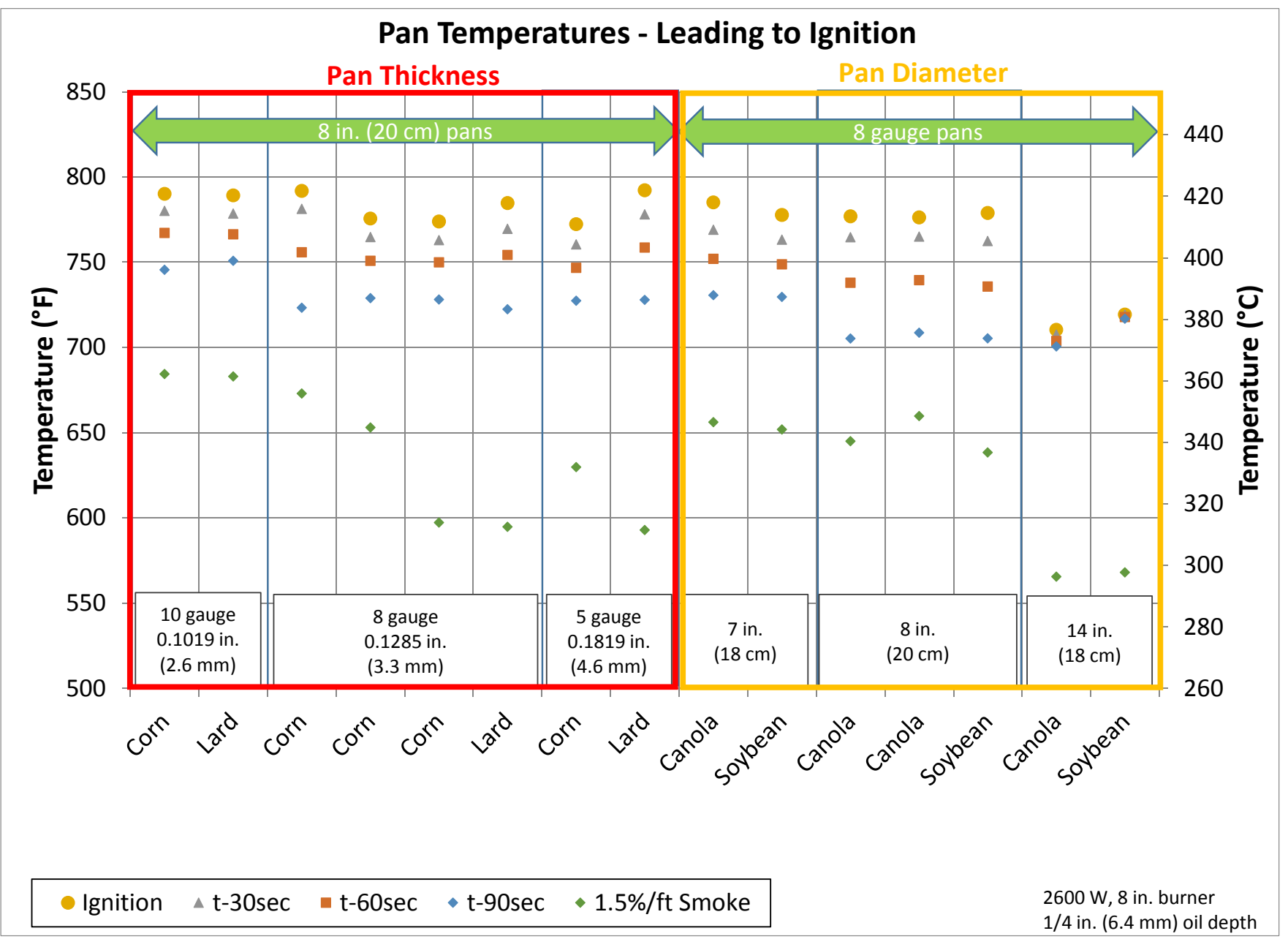

Figure 31 - Average pan temperatures approaching ignition for various pan thickness and diameters.

The average oil temperatures measured during the 90 seconds leading up until ignition and at the time of measured $1.5 \% / \mathrm{ft}(5 \% / \mathrm{m})$ smoke for various pan thicknesses and sizes are shown in Figure 32 . The averaged values reported include all spatial locations as well as data 3 seconds prior to and 3 seconds after each noted time.

No correlation was observed for the oil temperatures in pans of varying thickness. The corn oil temperatures were observed to decrease with reduced pan thickness, while the pork lard temperatures were observed to increase.

An increase in pan size and total oil volume (same depth) was observed to lower the measured oil ignition and smoke production temperatures, while increasing the oil temperatures in the time leading up to ignition. The oil temperatures at ignition decreased with pan thickness by $1^{\circ} \mathrm{F}\left(1^{\circ} \mathrm{C}\right)$ and $13^{\circ} \mathrm{F}$ $\left(7^{\circ} \mathrm{C}\right)$ for soybean and canola oils, respectively. The oil temperature 90 seconds before ignition, however, increased with increased pan size by $59^{\circ} \mathrm{F}\left(33^{\circ} \mathrm{C}\right)$ and $45^{\circ} \mathrm{F}\left(25^{\circ} \mathrm{C}\right)$ for soybean and canola oils, respectively. This is due to the slower heating rate of the larger pan and greater oil volume, demonstrating a reduced temperature gradient near ignition. 


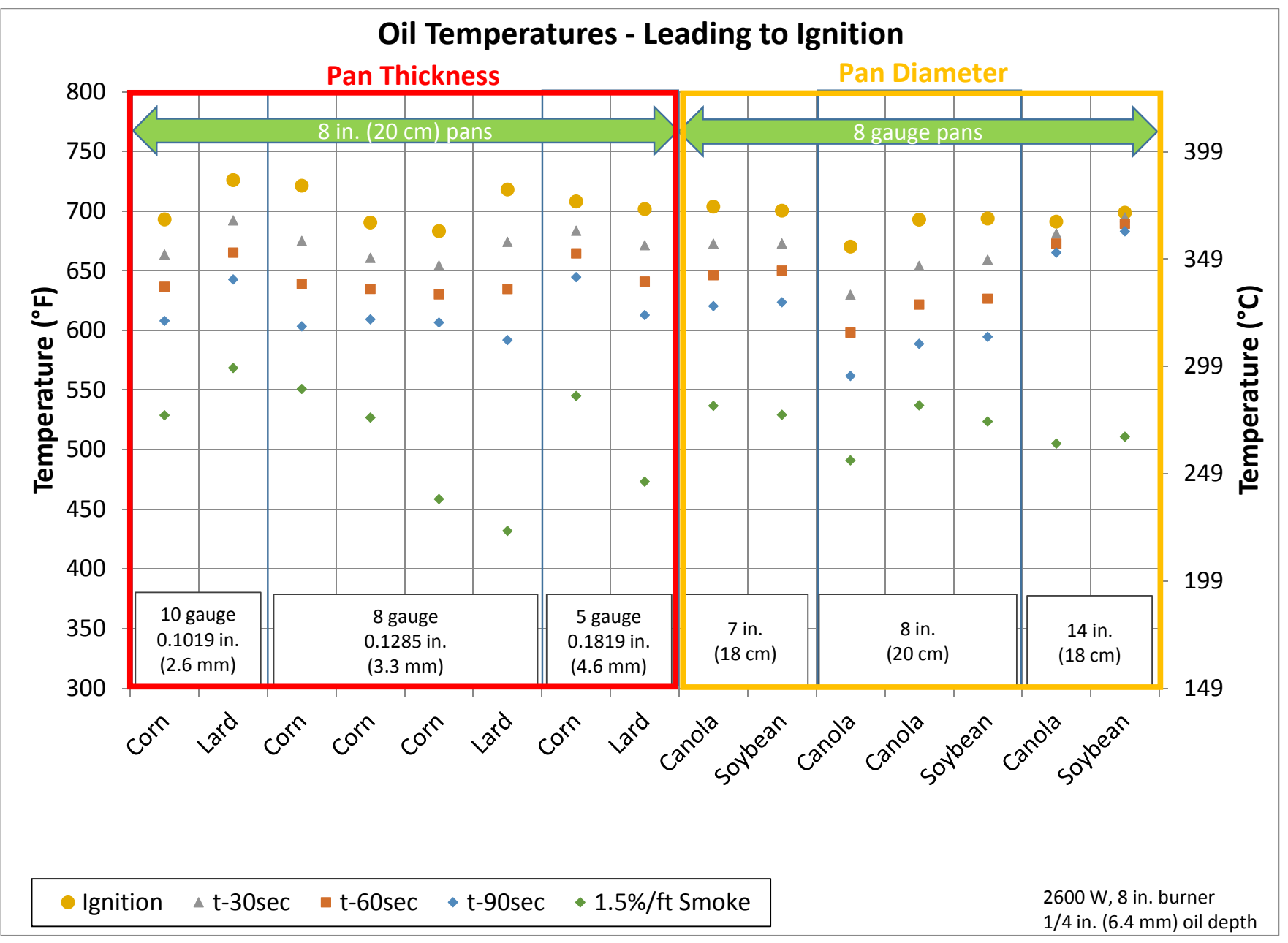

Figure 32 - Average oil temperatures approaching ignition for various range power levels.

The smoke obscuration measured during the 90 seconds leading up until ignition for various pan thicknesses and sizes are shown in Figure 33. No consistent trend was observed for the smoke concentrations in pans of varying thickness. The smoke concentrations from corn oil were lower prior to ignition but greater at ignition for the thinner gauge pan. The smoke concentrations measured for pork lard were greater at all measured times for the thinner gauge pan.

An increase in pan size and total oil volume (same depth) was observed to increase the smoke concentrations measured prior to and at ignition. The smoke obscuration measured 90 seconds before ignition for the 14 in. $(36 \mathrm{~cm})$ pans was nearly saturated, measuring nearly 5 times as much smoke as for the smaller 7 in. $(18 \mathrm{~cm})$ and 8 in. $(20 \mathrm{~cm})$ pans. 


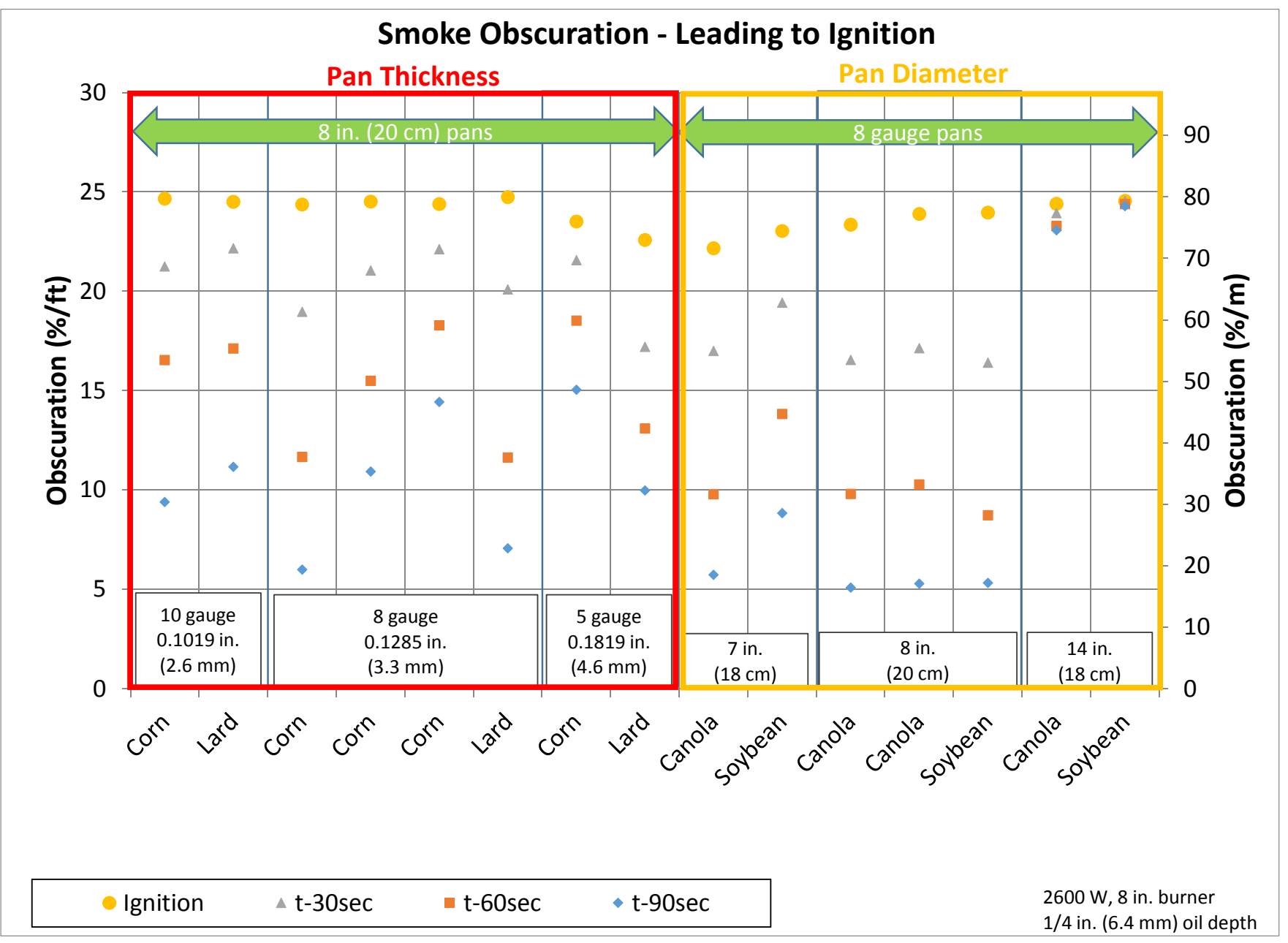

Figure 33 - Average smoke obscuration approaching ignition for various pan thicknesses and diameters.

\subsection{Pan Warping and Temperature Overshoot}

Testing was conducted to evaluate the ability to warp a pan using thermal cycling. A dry 10 gauge, 8 in. $(20 \mathrm{~cm})$ diameter pan was heated on the $8 \mathrm{in} .(20 \mathrm{~cm}) \mathrm{GE}$ burner until the pan temperature measured approximately $750^{\circ} \mathrm{F}-840^{\circ} \mathrm{F}\left(400^{\circ} \mathrm{C}-450^{\circ} \mathrm{C}\right)$. All power was then cutoff to the burner and the temperature overshoot was measured. When the temperature began to decrease it was dunked into a large water tank to initiate rapid cooling. This process was repeated through 30 heating and cooling cycles. Several of the heating cycles are shown with the measured range power output in Figure 34. 


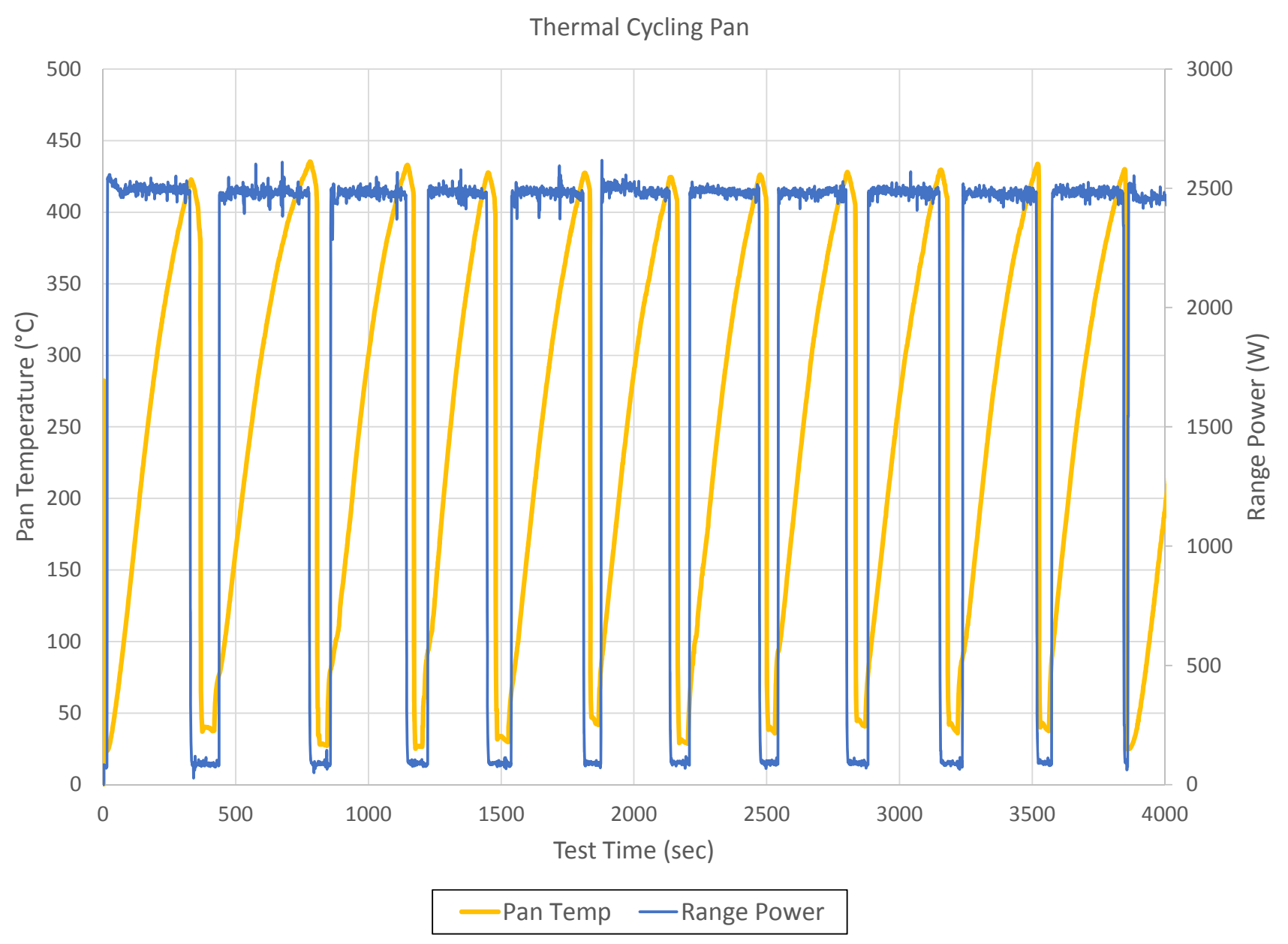

Figure 34 - Pan temperature and range power during rapid heating and cooling.

After 30 heating and cooling cycles were conducted, the pan flatness was measured about the center of the pan in a 2 in. $(5.1 \mathrm{~cm})$ radius. The maximum deviation measured across this area was $0.058 \mathrm{in}$. $(1.5 \mathrm{~mm})$ This is greater than the 0.006 times the diameter $(8 \times 0.006=0.048 \mathrm{in} .(20 \times 0.006=1.2 \mathrm{~mm}))$ threshold specified in UL 1026 [4]. It is less than the maximum deviation of $0.25 \mathrm{in}$. (6.4 mm) reported by a UL 858 task group for Technical Feasibility and Performance Goals (TFPG) for implementation of a contact temperature sensing device for range fire prevention [5].

During each cycle, the power was cut to the range and the temperature of the pan allowed to continue rising due to residual thermal gradients between the burner and pan surface. This effect is considered a temperature overshoot. A representative pan temperature overshoot is shown in Figure 35.

Temperature overshoots were generally observed to vary between $1-11^{\circ} \mathrm{F}\left(1-6^{\circ} \mathrm{C}\right)$ and occur over 3-10 seconds. The magnitude of the overshoot was generally observed to increase with reduced pan temperatures. At lower pan temperatures, the residual temperature gradient between the burner surface and the pan surface was increased, and the temperature overshoot would be greater in magnitude. The greatest overshoots were observed for pan shutoff temperatures of approximately $715^{\circ} \mathrm{F}\left(380^{\circ} \mathrm{C}\right)$. At lower pan cutoff temperatures, the overshoot may be further increased. 


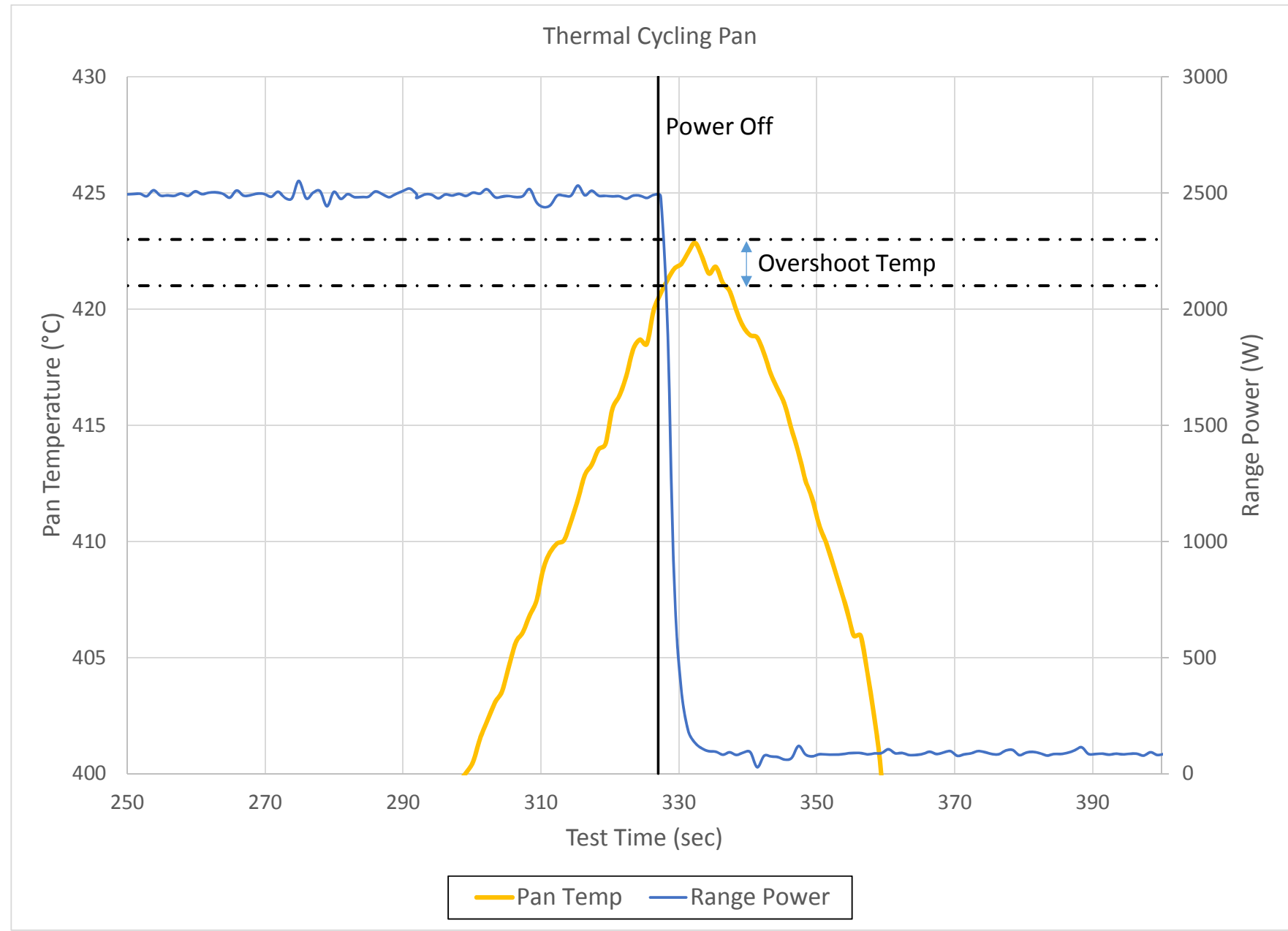

Figure 35 - Representative pan temperature overshoot.

\section{CORRELATIONS BETWEEN VARIABLES AND DATA}

The calculated correlations between the test variables and the measured data are shown in Table 3 (see Sec. 5.3.6). The magnitude of $r_{x y}$ indicates the strength of the correlations between the variables and data, ranging from -1 to 1 . The sign of the correlation indicates whether the test measurement was observed to increase or decrease with an increase in the variable. The correlation results provided should be used as a relative guide of whether a trend may exist, but additional test data is needed to establish more robust conclusions from these trends. In addition, the correlation results do not address the magnitude of the changes associated with the trends (i.e., the correlation strength does not reflect the quantitative slope of the change). For example, even if there is a strong correlation in the oil temperature relative to new and used oil or FFA, this does not imply that the change is significant relative to performance goals. 
Table 3 - Correlations Between Test Variables and Measured Data

\begin{tabular}{|c|c|c|c|c|c|}
\hline & \multirow[b]{2}{*}{ Measurement } & \multicolumn{4}{|c|}{$r_{x y}$} \\
\hline & & \%FFA & $\begin{array}{l}\text { Range } \\
\text { Power }\end{array}$ & $\begin{array}{c}\text { Pan } \\
\text { Thickness }\end{array}$ & $\begin{array}{c}\text { Pan } \\
\text { Diameter }\end{array}$ \\
\hline \multirow{5}{*}{$\begin{array}{l}\text { Average Pan } \\
\text { Temperatures }\end{array}$} & Ignition & -0.30 & 0.96 & -0.26 & -0.99 \\
\hline & Ignition - 30 seconds & 0.25 & 0.62 & 0.50 & -0.96 \\
\hline & Ignition -60 seconds & 0.45 & 0.83 & 0.42 & -0.91 \\
\hline & Ignition - 90 seconds & 0.38 & 0.82 & 0.34 & -0.90 \\
\hline & Smoke = 1.5\%/ft (5\%/m) & -0.84 & 0.09 & -0.61 & -0.98 \\
\hline \multirow{5}{*}{$\begin{array}{c}\text { Average Oil } \\
\text { Temperatures }\end{array}$} & Ignition & -0.24 & -0.48 & -0.08 & 0.03 \\
\hline & Ignition - 30 seconds & -0.15 & 0.90 & -0.32 & -0.89 \\
\hline & Ignition -60 seconds & -0.12 & 0.91 & -0.29 & -0.90 \\
\hline & Ignition - 90 seconds & -0.03 & 0.89 & -0.26 & -0.90 \\
\hline & Smoke $=1.5 \% / f t ~(5 \% / m)$ & -0.78 & -0.73 & -0.20 & -0.49 \\
\hline \multicolumn{2}{|c|}{ Heating Time Until Ignition } & -0.08 & -0.67 & 0.51 & 0.95 \\
\hline \multicolumn{2}{|c|}{ Time Between 1.5\%/ft (5\%/m) Smoke and Ignition } & 0.01 & -0.69 & 0.54 & 0.95 \\
\hline \multicolumn{2}{|c|}{ Time Between 5 ppm CO and Ignition } & -0.17 & -0.12 & -0.07 & 0.26 \\
\hline \multicolumn{2}{|c|}{ Smoke Obscuration $60 \mathrm{sec}$ before ignition } & 0.67 & -0.79 & -0.04 & 0.94 \\
\hline
\end{tabular}

The percent FFA was observed to have the greatest overall impact on the pan and oil temperatures at the time $1.5 \% / \mathrm{ft}(5 \% / \mathrm{m})$ smoke was measured. Strong negative correlations were observed to exist, therefore increases in FFA content decreased the pan and oil temperatures resulting in smoke production. This also resulted in increased smoke concentrations 60 seconds before ignition, also showing a strong positive correlation with percent FFA.

The range power was observed to have a strong positive correlation with the average pan temperature at ignition, but a negative correlation with the oil temperature at ignition. Reduced power would result in a reduced temperature gradient between the pan and the oil, therefore increasing pan temperatures while decreasing oil temperatures. Increases in the range power also increase the differences between the pan and oil temperatures prior to ignition. More power resulted in steeper slopes in the temperatures approaching ignition.

The pan thickness was found to correlate most strongly with the average pan temperature at the time of $1.5 \% / \mathrm{ft}(5 \% / \mathrm{m})$ smoke in the hood. A negative correlation was observed, with the average pan temperature decreasing with increasing pan thickness. The pan thickness was also observed to correlate positively with the time to ignition and the time between the measurement of $1.5 \% / \mathrm{ft}(5 \% / \mathrm{m})$ smoke and ignition.

The pan diameter was observed to have very strong negative correlation with the pan temperature at the time of ignition, but to have no correlation with the oil temperature at ignition. The difference in pan and oil temperatures were also found to negatively correlate with the pan size, with temperatures much closer to the ignition temperatures measured up to 90 seconds before ignition. The total heating time, the time between $1.5 \% / \mathrm{ft}(5 \% / \mathrm{m})$ and ignition, and the smoke obscuration 60 seconds before ignition were all observed to correlate strongly with the pan diameter. 


\section{REFERENCES}

1. Ahrens, M. "Home Fires Involving Cooking Equipment," National Fire Protection Association, Quincy, MA, Nov 2012.

2. Dinaburg, J. and Gottuk, D.T., "Home Cooking Fire Mitigation: Technology Assessment - Final Report," prepared for The Fire Protection Research Foundation, Quincy, MA, HAI Project \#1DTG02049.006, Oct 31, 2011.

3. Bockisch, Michael, "Fats and Oils Handbook," AOCS Press, Champaign, IL 1993, p.96.

4. Underwriters Laboratory, Inc., "UL 1026, Electrical Household Cooking and Food Serving Appliances, Section 41.2.9.1," Jan 27, 2012.

5. Underwriters Laboratory Inc., "UL 858-04-01, Technical Feasibility Performance Goals," 2002. 